\title{
The Pasadena Aerosol Characterization Observatory (PACO): chemical and physical analysis of the Western Los Angeles basin aerosol
}

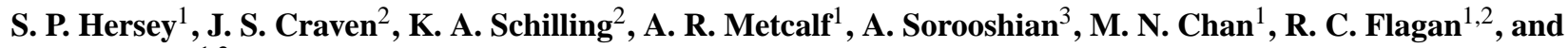 \\ J. H. Seinfeld ${ }^{1,2}$ \\ ${ }^{1}$ Division of Engineering and Applied Science, California Institute of Technology, Pasadena, CA, USA \\ ${ }^{2}$ Division of Chemistry and Chemical Engineering, California Institute of Technology, Pasadena, CA, USA \\ ${ }^{3}$ Department of Chemical and Environmental Engineering, University of Arizona, Tucson, AZ, USA
}

Received: 3 February 2011 - Published in Atmos. Chem. Phys. Discuss.: 18 February 2011

Revised: 16 June 2011 - Accepted: 25 June 2011 - Published: 1 August 2011

\begin{abstract}
The Pasadena Aerosol Characterization Observatory (PACO) represents the first major aerosol characterization experiment centered in the Western/Central Los Angeles Basin. The sampling site, located on the campus of the California Institute of Technology in Pasadena, was positioned to sample a continuous afternoon influx of transported urban aerosol with a photochemical age of $1-2 \mathrm{~h}$ and generally free from major local contributions. Sampling spanned 5 months during the summer of 2009, which were broken into 3 regimes on the basis of distinct meteorological conditions. Regime I was characterized by a series of low pressure systems, resulting in high humidity and rainy periods with clean conditions. Regime II typified early summer meteorology, with significant morning marine layers and warm, sunny afternoons. Regime III was characterized by hot, dry conditions with little marine layer influence. Regardless of regime, organic aerosol (OA) is the most significant constituent of nonrefractory submicron Los Angeles aerosol (42, 43, and $55 \%$ of total submicron mass in regimes I, II, and III, respectively). The overall oxidation state remains relatively constant on timescales of days to weeks $(\mathrm{O}: \mathrm{C}=0.44 \pm 0.08$, $0.55 \pm 0.05$, and $0.48 \pm 0.08$ during regimes I, II, and III, respectively), with no difference in $\mathrm{O}: \mathrm{C}$ between morning and afternoon periods. Periods characterized by significant morning marine layer influence followed by photochemically favorable afternoons displayed significantly higher aerosol mass and $\mathrm{O}: \mathrm{C}$ ratio, suggesting that aqueous processes may
\end{abstract}

Correspondence to: J. H. Seinfeld (seinfeld@caltech.edu) be important in the generation of secondary aerosol and oxidized organic aerosol (OOA) in Los Angeles. Online analysis of water soluble organic carbon (WSOC) indicates that water soluble organic mass (WSOM) reaches maxima near 14:00-15:00 local time (LT), but the percentage of AMS organic mass contributed by WSOM remains relatively constant throughout the day. Sulfate and nitrate reside predominantly in accumulation mode aerosol, while afternoon SOA production coincides with the appearance of a distinct fine mode dominated by organics. Particulate $\mathrm{NH}_{4} \mathrm{NO}_{3}$ and $\left(\mathrm{NH}_{4}\right)_{2} \mathrm{SO}_{4}$ appear to be $\mathrm{NH}_{3}$-limited in regimes I and II, but a significant excess of particulate $\mathrm{NH}_{4}^{+}$in the hot, dry regime III suggests less $\mathrm{SO}_{4}^{2-}$ and the presence of either organic amines or $\mathrm{NH}_{4}^{+}$-associated organic acids. CToF-AMS data were analyzed by Positive Matrix Factorization (PMF), which resolved three factors, corresponding to a hydrocarbon-like OA (HOA), semivolatile OOA (SVOOA), and low-volatility OOA (LV-OOA). HOA appears to be a periodic plume source, while SV-OOA exhibits a strong diurnal pattern correlating with ozone. Peaks in SV-OOA concentration correspond to peaks in DMA number concentration and the appearance of a fine organic mode. LV-OOA appears to be an aged accumulation mode constituent that may be associated with aqueous-phase processing, correlating strongly with sulfate and representing the dominant background organic component. Periods characterized by high SV-OOA and LV-OOA were analyzed by filter analysis, revealing a complex mixture of species during periods dominated by SV-OOA and LV-OOA, with LV-OOA periods characterized by shorter-chain dicarboxylic acids (higher $\mathrm{O}: \mathrm{C}$ ratio), as well as appreciable amounts of nitrate- and

Published by Copernicus Publications on behalf of the European Geosciences Union. 
sulfate-substituted organics. Phthalic acid was ubiquitous in filter samples, suggesting that PAH photochemistry may be an important SOA pathway in Los Angeles. Aerosol composition was related to water uptake characteristics, and it is concluded that hygroscopicity is largely controlled by organic mass fraction (OMF). The hygroscopicity parameter $\kappa$ averaged $0.31 \pm 0.08$, approaching 0.5 at low $\mathrm{OMF}$ and 0.1 at high OMF, with increasing OMF suppressing hygroscopic growth and increasing critical dry diameter for CCN activation $\left(\mathrm{D}_{d}\right)$. An experiment-averaged $\kappa_{\mathrm{org}}$ of 0.14 was calculated, indicating that the highly-oxidized organic fraction of aerosol in Los Angeles is appreciably more hygroscopic than previously reported in urban areas. Finally, PACO will provide context for results forthcoming from the CalNex field campaign, which involved ground sampling in Pasadena during the spring and summer of 2010.

\section{Introduction}

Over half the world's population lives in urban areas, and that fraction is expected to increase in coming decades (Bremner et al., 2009). There have been a number of recent coordinated studies focused on characterizing particulate air quality in major urban areas, such as Pittsburgh, PA (Pittsburgh Air Quality Study, PAQS; e.g., Pekney et al., 2006; Bein et al., 2006; Wittig et al., 2004; Cabada et al., 2004; Modey et al., 2004), Los Angeles, CA (Southern California Air Quality Study, SCAQS; e.g., Eldering et al., 1994; Watson et al., 1994; Chow et al., 1994; Turpin and Huntzicker, 1991; Southern California Ozone Study 1997, SCOS97-NARSTO; e.g., Croes and Fujita, 2003; Liu et al., 2000; Pastor et al., 2003; Hughes et al., 2002; Secondary Organic Aerosol in Riverside, SOAR; e.g., Docherty et al., 2008; Eatough et al., 2008; Denkenberger et al., 2007), Mexico City, Mexico (Megacity Initiative: Local and Global Research Observations, MILAGRO; e.g., DeCarlo et al., 2008; Stone et al., 2008; Aiken et al., 2009), and Beijing, China (Campaign of Air Quality Research in Beijing, CAREBEIJING; e.g., Matsui et al., 2009; Yue et al., 2009; van Pinxteren et al., 2009).

The Los Angeles metropolitan area, with a population of over 17 million people, has long been considered a laboratory for air quality. Once the quintessential example of classic photochemical smog, the Los Angeles area has, as a result of decades of aggressive emission controls, reached a point where 8-h US National Ambient Air Quality Standard ozone exceedances have decreased from over 200 days/year in the 1980s to 120 in 2008 (AQMD, 2010). Nonetheless, this area remains one in which particulate matter levels continue to regularly exceed air quality standards, with annual $\mathrm{PM}_{2.5}$ averages exceeding the national standard every year from 2000-2008 in Los Angeles County (CARB, 2010).

The Los Angeles Basin is generally characterized as source-rich in its western area, with prevailing west and southwest winds transporting emissions downwind toward the east and northeast ( $\mathrm{Lu}$ and Turco, 1995). Three major coordinated studies have been undertaken to characterize Los Angeles air quality, in addition to ongoing work to describe facets of Los Angeles aerosol (Table 1). The majority of previous studies in the Los Angeles Basin have been centered in the downwind, eastern part of the basin, roughly $60 \mathrm{~km}$ east of downtown Los Angeles. The aerosol in this region is predominantly aged, with local contributions as well.

A major source of gaseous and particulate pollution in the Los Angeles area is mobile source emissions. The Los Angeles aerosol undergoes dramatic evolution from nighttime/morning periods to the photochemically active afternoon, characterized by changes in both its microphysical properties and composition. Overall, the submicron aerosol is dominated by organic aerosol (OA), which is predominantly secondary in origin (SOA), and nitrate (Docherty et al., 2008), with smaller amounts of sulfate and a minor chloride contribution. Primary marine and secondary sulfate aerosol are expected to contribute a relatively uniform loading of sulfate across the Los Angeles Basin (Watson et al., 1994). Marine sulfate is expected to be contributed by natural primary processes (biological, sea spray, bubble bursting), with anthropogenic shipping-related emissions contributing a varied and often significant loading of sulfate (Ault et al., 2010).

The Pasadena Aerosol Characterization Observatory experiment (PACO) was conducted from May-August 2009 in Pasadena, CA, in the north-central/north-western portion of the Los Angeles Basin, $16 \mathrm{~km}$ NE of downtown Los Angeles. Aerosol physics, composition, and hygroscopicity were measured during 54 days that spanned three distinct regimes of the annual meteorological cycle. A major forest fire occurred at the end of the sampling period, starting on 26 August and consuming over 160000 acres of the Angeles National Forest before containment on 16 October. Named the "Station Fire", its southernmost extent was roughly $8 \mathrm{~km}$ from the sampling site, and emissions from the fire impacted the sampling site with periodic heavy smoke, soot, and ash. Results from PACO sampling during the Station Fire will be presented in subsequent work.

PACO represents the first prolonged experiment aimed at characterizing the aerosol near the source-rich western/central part of the Los Angeles basin; comparisons with previous studies in downwind areas will help determine the rate of aerosol generation from Los Angeles sources, as well as the nature of aerosol transformations with downwind transport. Further, the PACO study was well-timed to precede the 2010 CalNex field campaign (http://www.esrl.noaa. gov/csd/calnex/).

This paper presents an overview of the PACO experiment. Aerosol number and volume distributions measured by a differential mobility analyzer (DMA) exhibit distinct diurnal patterns, and composition data from an Aerodyne CompactTime-of-Flight Aerosol Mass Spectrometer (C-ToF AMS) 
Table 1. Previous Los Angeles air quality studies and major findings relative to particulate matter.

\begin{tabular}{|c|c|c|}
\hline Study & Date & Major aerosol findings \\
\hline $\begin{array}{l}\text { Southern California } \\
\text { Air Quality Study } \\
\text { (SCAQS) }\end{array}$ & $\begin{array}{l}\text { Summer/ } \\
\text { fall } \\
1987\end{array}$ & $\begin{array}{l}\text { - SOA/OA } \sim 40 \% \text { in summer afternoon (Turpin and Huntzicker, 1991) } \\
\text { - Primary vehicle exhaust is the major aerosol component } \\
\text { near PACO sampling site (Watson et al., 1994) } \\
\text { - } 20-32 \% \text { of } \mathrm{PM}_{10} \text { is } \mathrm{SO}_{4}^{2-} \text { and } \mathrm{NO}_{3}^{-} \text {(Watson et al., 1994) }\end{array}$ \\
\hline $\begin{array}{l}\text { Southern California } \\
\text { Ozone Study }\end{array}$ & $\begin{array}{l}\text { Summer } \\
1997\end{array}$ & $\begin{array}{l}\text { - Submicron organic mode evolves during periods of intense photochemistry, } \\
\text { coincident with maximum } \mathrm{O}_{3} \text { (Pastor et al., 2003) } \\
\text { - } \mathrm{NH}_{4} \mathrm{NO}_{3} \text { and organics added to submicron aerosol with photochemical age } \\
\text { (Pastor et al., 2003) } \\
\text { - } \mathrm{NH}_{3} \text { sources in eastern basin enhance particulate } \mathrm{NH}_{4} \mathrm{NO}_{3} \text { (Hughes et al., 2002) }\end{array}$ \\
\hline $\begin{array}{l}\text { Secondary Organic } \\
\text { Aerosol in River- } \\
\text { side (SOAR-1, 2) }\end{array}$ & $\begin{array}{l}\text { Aug, } \\
\text { Nov } \\
2005\end{array}$ & $\begin{array}{l}\text { - Significant diurnal changes in organic aerosol, with species more reduced in } \\
\text { the morning and more oxidized in the afternoon (DeCarlo et al., 2006) } \\
\text { - Oligomers detected in aged, acidic particles (Denkenberger et al., 2007) } \\
\text { - SOA/OA }=70-90 \% \text { at midday and } \sim 45 \% \text { during morning commute; } \\
\text { SOAR average }=74 \% \text { (Docherty et al., 2008) }\end{array}$ \\
\hline Individual studies & $\begin{array}{l}\text { 1999, } \\
2001-2002\end{array}$ & $\begin{array}{l}\text { - Complex, multi-modal GF data in Pasadena (Cocker et al., 2001) } \\
\text { - SOA }>50 \% \text { of total } \mathrm{PM}_{2.5} \text { in eastern basin (Sawant et al., 2004; Na et al., 2004) }\end{array}$ \\
\hline
\end{tabular}

indicate that these patterns are associated largely with the production of semivolatile oxidized organic species during photochemically active daytime periods. AMS-based Positive Matrix Factorization (PMF) results indicate that the character of OA in Los Angeles is overwhelmingly oxidized and secondary, and the high time resolution data allow for investigation of the daily evolution of OA components. U1tra Performance Liquid Chromatography/Electrospray Ionization Time-of-Flight High-Resolution Mass Spectrometry (UPLC/ESI-TOFMS) analysis of high-volume filter samples provides further evidence for diurnal changes in the character of OA, while thermal-optical analysis of low-volume, denuded filter samples reveals the magnitude of organic and elemental carbon in morning versus afternoon sampling periods. A particle-into-liquid sampler with offline ion chromatography analysis (PILS-IC) provides quantitative water-soluble inorganic ion composition during PACO, while a PILS coupled with online total organic carbon analysis (PILS-TOC) measured total water soluble organic carbon measurements during the third regime. Finally, trends in aerosol hygroscopicity indicate the degree to which changes in the magnitude and character of OA affect particle water uptake. PACO results are compared with previous aerosol characterization experiments in the Los Angeles Basin, with major differences attributed to regional variations in both source profiles and degree of aging.

\section{Methods}

Sampling was conducted on the Caltech campus in Pasadena, at $34.138^{\circ} \mathrm{N}, 118.124^{\circ} \mathrm{W}$. Caltech is located in the west- ern/central portion of the Los Angeles Basin, $8 \mathrm{~km}$ south of the San Gabriel Mountains and $16 \mathrm{~km} \mathrm{NE}$ of downtown Los Angeles in the San Gabriel Valley. The 210 freeway is located $1.5 \mathrm{~km}$ north of the site, with heavy traffic between the hours of 08:00 and 09:00 LT, and then again between 15:00 and 19:00 LT. Prevailing daytime winds are from the $\mathrm{W}$ or SW, minimizing the impact of primary emissions from the 210 freeway at the sampling site, but overnight NW winds occasionally bring freeway emissions to Caltech. Other than this periodic impact from local primary emissions, the Pasadena aerosol is representative of transported urban particulate pollution from near the source-rich downtown area of the Los Angeles Basin.

PACO sampling took place between May and August of 2009, spanning the transition from spring to summer meteorological regimes. PACO was separated into three distinct analysis periods on the basis of meteorology, as summarized in Table 2.

\subsection{Meteorology}

Hourly meteorological data were downloaded from the Remote Automatic Weather Stations (RAWS) archive from the Western Regional Climate Center at the Desert Research Institute (DRI, Reno, Nevada). Data are from the Santa Fe Dam station, approximately $16 \mathrm{~km}$ east of the sampling site in the San Gabriel Valley, and are available online: http: //www.raws.dri.edu/cgi-bin/rawMAIN.pl?caCSFD. 
Table 2. PACO sampling regimes (2009).

\begin{tabular}{|c|c|c|}
\hline Regime & Dates & Characteristics \\
\hline $\begin{array}{l}\text { Springtime } \\
\text { meteorology }\end{array}$ & $\begin{array}{l}22 \text { May } \\
\text { to } 12 \text { Jun }\end{array}$ & $\begin{array}{l}\text { - Basin impacted by a series of low pressure systems } \\
\text { - Cutoff low brought rare springtime precipitation and cleaner atmosphere } \\
\text { - Persistent cloudcover, unstable atmosphere } \\
\text { - Low daytime temperatures, high } \mathrm{RH} \text {, and limited photochemistry } \\
\text { - High visibility with low } \mathrm{O}_{3}\end{array}$ \\
\hline $\begin{array}{l}\text { Early } \\
\text { summer/ } \\
\text { marine } \\
\text { influence }\end{array}$ & $\begin{array}{l}18 \mathrm{Jun} \\
\text { to } 7 \mathrm{Jul}\end{array}$ & $\begin{array}{l}\text { - Limited impact from low pressure systems } \\
\text { - Morning marine layer eroded several hours after sunrise } \\
\text { - Higher daytime temperatures, slightly lower } \mathrm{RH} \text {, and photochemically } \\
\text { active afternoons } \\
\text { - Hazy afternoons with increased } \mathrm{O}_{3}\end{array}$ \\
\hline $\begin{array}{l}\text { Photo- } \\
\text { chemically } \\
\text { active }\end{array}$ & $\begin{array}{l}10 \mathrm{Jul} \\
\text { to } 4 \mathrm{Aug}\end{array}$ & $\begin{array}{l}\text { - Semi-permanent high pressure over Southern California } \\
\text { - Little marine moisture and infrequent, quickly-eroded marine layer } \\
\left.\text { - High daytime temp. (often exceeding } 35^{\circ} \mathrm{C}\right) \text {, very low daytime } \mathrm{RH}(\leq 15 \%) \text {, } \\
\text { photochemically active days } \\
\text { - Decreased visibility, high afternoon } \mathrm{O}_{3}\end{array}$ \\
\hline
\end{tabular}

\subsection{Gas-phase data}

Hourly $\mathrm{O}_{3}, \mathrm{NO}_{\mathrm{x}}$, and $\mathrm{CO}$ data were obtained from the California Air Resources Board's Pasadena (South Wilson) monitoring site located on the Caltech campus. Data are available online at http://www.arb.ca.gov/adam/hourly/hourly1.php.

\subsection{Differential mobility analyzer}

Particle size distribution measurements were performed with a cylindrical scanning differential mobility analyzer (TSI Model 3081) upstream from a condensation particle counter (TSI Model 3760). A logarithmic scan from a mobility diameter of $15 \mathrm{~nm}$ to $815 \mathrm{~nm}$ was completed every $237 \mathrm{~s}$. The sheath and excess flows of $2.51 \mathrm{~min}^{-1}$ were used, with a 10:1 flow rate ratio of sheath-to-aerosol.

\subsection{Aerosol mass spectrometer}

An Aerodyne compact time-of-flight aerosol mass spectrometer (C-ToF-AMS; Drewnick et al., 2005; Canagaratna et al., 2007) measured aerosol composition and size information for 54 days during PACO. The AMS collects sub-micron particles via an aerodynamic lens into a particle sizing chamber, after which particles are vaporized and ionized by a heater and filament assembly. Aerosol fragments are then orthogonally extracted into an ion time-of-flight chamber where they are detected and interpreted as mass spectra. Adjustments to the AMS fragmentation table were made regularly, based on 21 filter sample periods over the course of PACO (Allan et al., 2004b). Additionally, thirteen ionization efficiency calibrations were made using ammonium nitrate solutions. The AMS sulfate measurement was compared to sulfate concentrations from the PILS-IC, resulting in an AMS collection efficiency (CE) of 0.5. This CE is in agreement with previous ambient studies (Huffman et al., 2005; Drewnick et al., 2003; Allan et al., 2004a). AMS data were processed with the ToF-AMS Analysis Toolkit in Igor Pro 6 (Wavemetrics, Lake Oswego, OR).

\subsection{Positive matrix factorization analysis}

The dominant fraction of submicron nonrefractory aerosol is organic in most urban areas (Zhang et al., 2007). OA comprises a multitude of compounds, such that characterization by identification of each component is not currently possible (Schauer et al., 1996). Positive Matrix Factorization (PMF) has been used to deconvolve AMS mass spectra in order to identify classes of organic compounds that constitute OA (Paatero and Tapper, 1994; Paatero, 1997; Ulbrich et al., 2009). PMF solutions represent linear, positive combinations of mass spectra that describe variability in data, and AMS-based PMF results from most sites resolve factors whose mass spectra have characteristics of hydrocarbon-like OA (HOA) and oxygenated OA (OOA), with other factors such as biomass burning OA (BBOA) occurring in some areas (Zhang et al., 2007). OOA can often be further deconvolved into low-volatility OOA (LV-OOA) and semivolatile OOA (SV-OOA), broadly representing aged, transported, and highly oxidized OA and fresher, local, and less oxidized OA, respectively ( $\mathrm{Ng}$ et al., 2010). AMS measurements, in conjunction with PMF analysis, allow for investigation of the diurnal evolution of OA and rapid changes in OA occurring during photochemically intense periods. Further, the combination of PMF solutions with analysis of the relative abundance of mass-to-charge $(\mathrm{m} / \mathrm{z}$ ) ratios 43 and 44 can be used as an aerosol aging diagnostic that allows comparison between locations (Ng et al., 2010). 
For the PACO dataset, bulk AMS organic aerosol was prepared and then processed using the PMF2.exe algorithm (Paatero and Tapper, 1994). Solutions from the PMF algorithm were compared to meteorological variables and chemical tracers, as well as previously published mass spectra, using the PMF Evaluation Tool (PET Ulbrich et al., 2009). The strategic procedure for probing the PMF solution space is provided in Appendix A.

\subsection{PILS-IC}

A particle-into-liquid sampler coupled with off-line ion chromatography (PILS-IC, Sorooshian et al., 2006) sampled during 4-h periods (07:00-11:00 and 15:00-19:00 LT), providing quantitative measurements of inorganic and organic ions. The PILS samples ambient air through a $1 \mu \mathrm{m}$ cut size impactor and three denuders (URG and Sunset Laboratory) designed to remove inorganic and organic gases that might bias aerosol measurements. Sampled air is then exposed to high water supersaturation in a steam chamber, where particles grow sufficiently large to be collected by inertial impaction before being delivered to vials held on a rotating carousel. Samples were collected every $30 \mathrm{~min}$, and were stored at $2{ }^{\circ} \mathrm{C}$ until analysis by a dual IC system (Dionex ICS-2000). PILSIC data from PACO are used primarily to determine collection efficiency corrections for the AMS and are not presented in detail here.

\subsection{PILS-TOC}

Water-soluble organic carbon (WSOC) was quantified during 12-h periods (07:00-19:00 LT) using a PILS (Brechtel Manufacturing Inc.) coupled to a Sievers Model 800 Total Organic Carbon (TOC) Analyzer (PILS-TOC). Details of this technique are described in detail by (Sullivan et al., 2004, 2006). Briefly, particles smaller than $2.5 \mu \mathrm{m}$ in diameter are sampled by the PILS and passed immediately through an organic carbon denuder (Sunset Laboratory Inc.) to remove organic vapors. Particles are grown into droplets, collected by inertial impaction, and delivered to a TOC analyzer for quantification of WSOC, with data reported every $6 \mathrm{~min}$. To account for dilution of the PILS liquid wash flow to the TOC analyzer owing to collected drops and condensation on the PILS droplet impactor, a constant dilution factor of 1.15 is assumed. This factor is based on measurements with an independent PILS system coupled to ion chromatography, a technique that can more precisely quantify the dilution factor. The reported WSOC levels are the difference between the measured and background concentrations. Contamination in the MQ water was the main component of the background levels, which were assumed to be constant between periodic background measurements. The overall measurement uncertainty is estimated to be approximately $10 \%$. The PILSTOC was employed during the final, photochemically active regime of PACO, from 10 July to 4 August.

\subsection{Filter sampling}

Both high- and low-volume filter samples were collected during 4-h sampling periods (07:00-11:00 and 15:00-19:00 LT). High-volume $\left(12501 \mathrm{~min}^{-1}\right)$ samples were collected with a Tisch TE-6001 sampler fitted with a $\mathrm{PM}_{2.5}$ fractionater, using Whatman Quartz Microfibre Filters (cat. \#1851$865)$. Low volume $\left(15.91 \mathrm{~min}^{-1}\right.$ ) samples were collected on $47 \mathrm{~mm}$ PALL Life Sciences Pallflex membrane filters, downstream from a Sunset Laboratory parallel-plate carbon filter denuder. Sampling was carried out according to the IMPROVE_A protocol, except that oven limitations forced filters to be pre-baked at $300^{\circ} \mathrm{C}$ before sampling. Despite the lower pre-baking temperature, subsequent analysis of prebaked filters revealed $\leq 0.01 \mu \mathrm{g}$ of organic carbon (OC) and elemental carbon (EC). After sampling, filters were wrapped in two layers of aluminum foil and stored at $-20^{\circ} \mathrm{C}$ until analysis.

Low- and high- volume samples were analyzed for OC and EC via thermal-optical analysis (TOA) with a Sunset OC-EC TOA analyzer, following the IMPROVE_A temperature and calibration protocols. High volume quartz filters were also analyzed by Ultra Performance Liquid Chromatography/Electrospray Ionization Time-of-Flight HighResolution Mass Spectrometry (UPLC/ESI-TOFMS). Oneeighth of each filter was extracted with high-purity methanol under ultrasonication for $45 \mathrm{~min}$. Filter extracts were filtered through a PALL Life Sciences Acrodisc CR 25-mm syringe filter (PTFE membrane, 0.2-mm pore size) into a scintillation vial. The filtered extracts were blown dry under a gentle nitrogen stream at ambient temperature. The residue was reconstituted with $50: 50 \mathrm{v} / \mathrm{v}$ methanol with $0.1 \%$ acetic acid and water. Blank filters were extracted and treated in the same manner as the field samples. Extracts were analyzed by a Waters ACQUITY ultra performance liquid chromatography (UPLC) system, coupled with a Waters LCT Premier TOF mass spectrometer equipped with an electrospray ionization (ESI) source, allowing for accurate mass measurements (i.e., determination of molecular formulas) to be obtained for each observed ion. Extracts were analyzed by UPLC/ESI TOFMS operated in both negative and positive ion modes. Details of operation protocols, including column information and chromatographic method for the UPLC/ESITOFMS are given by Surratt et al. (2008).

\subsection{Hygroscopicity}

Hygroscopicity measurements were carried out with the Differential Aerosol Sizing and Hygroscopicity Spectrometer Probe (DASH-SP, Brechtel Mfg), which is described by Sorooshian et al. (2008). Briefly, ambient particles pass through a nafion dryer before size-selection by a cylindrical, single-classification differential mobility analyzer (DMA). The resulting monodisperse aerosol is split into five separate flows - one providing a redundant measurement of total 


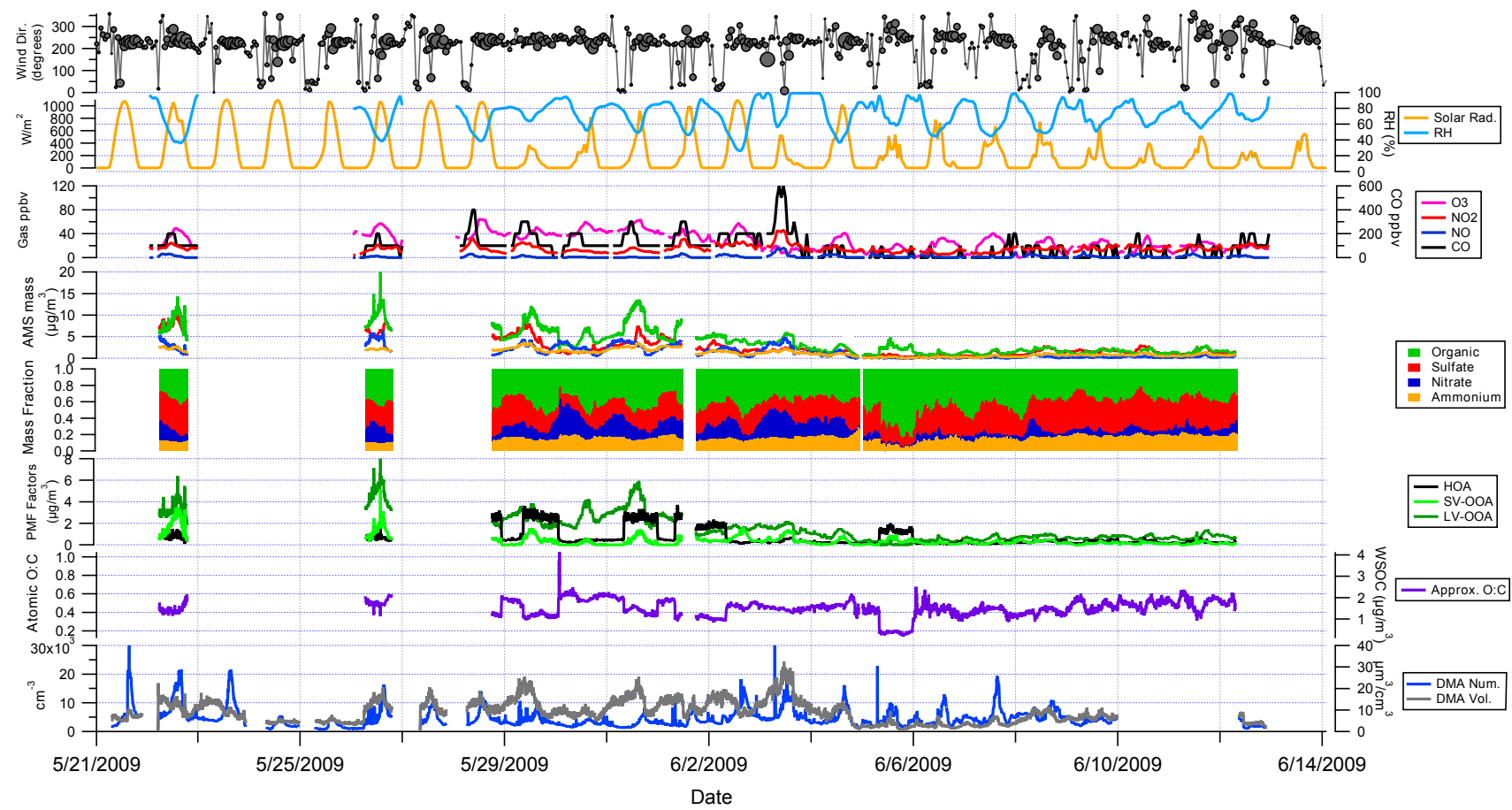

Fig. 1a. Regime I (wind direction marker size proportional to wind speed; max size $=20 \mathrm{~km} \mathrm{~h}^{-1}$ ).

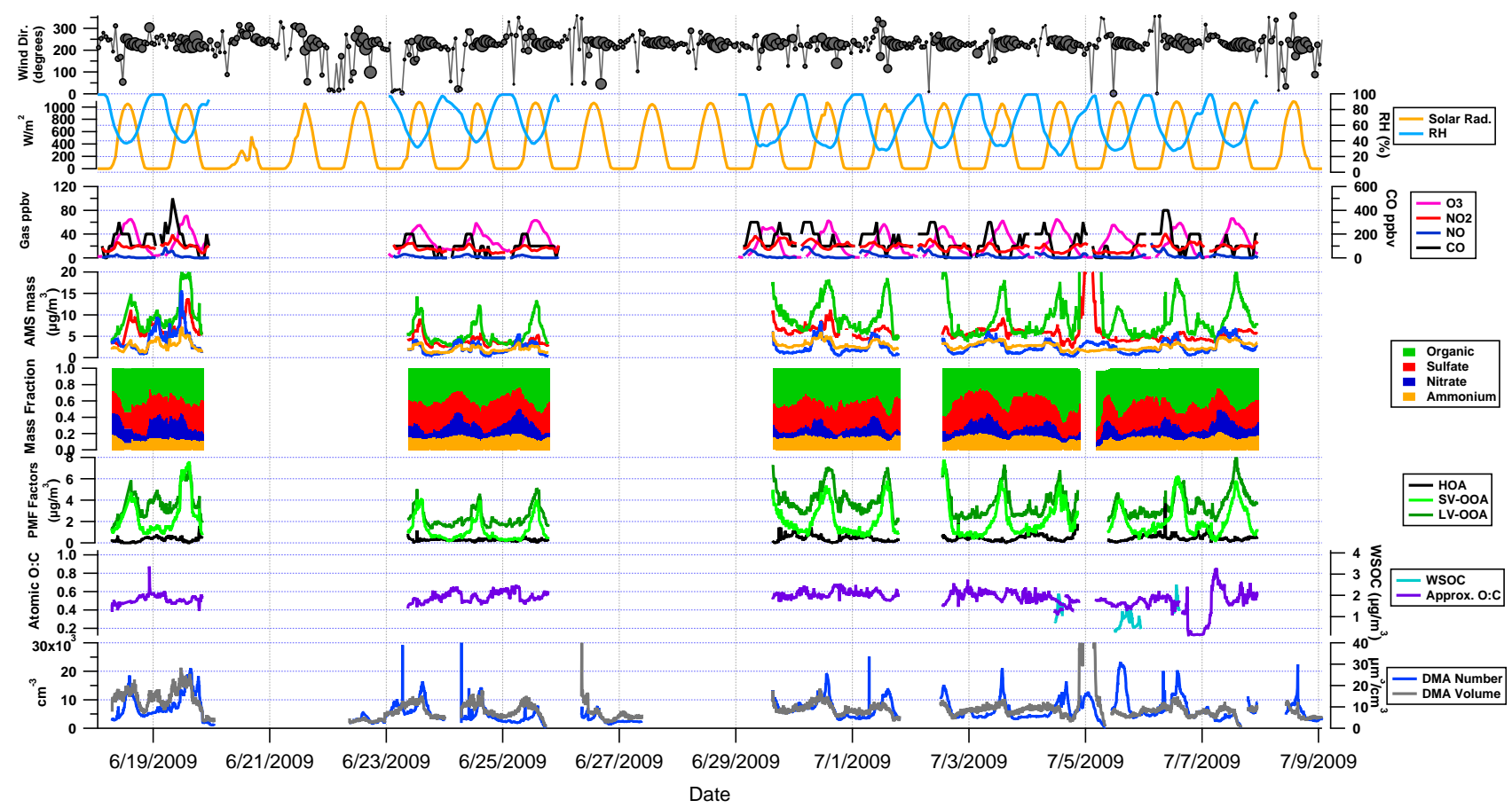

Fig. 1b. Regime II (wind direction marker size proportional to wind speed; $\max$ size $=20 \mathrm{~km} \mathrm{~h}^{-1}$ ). 


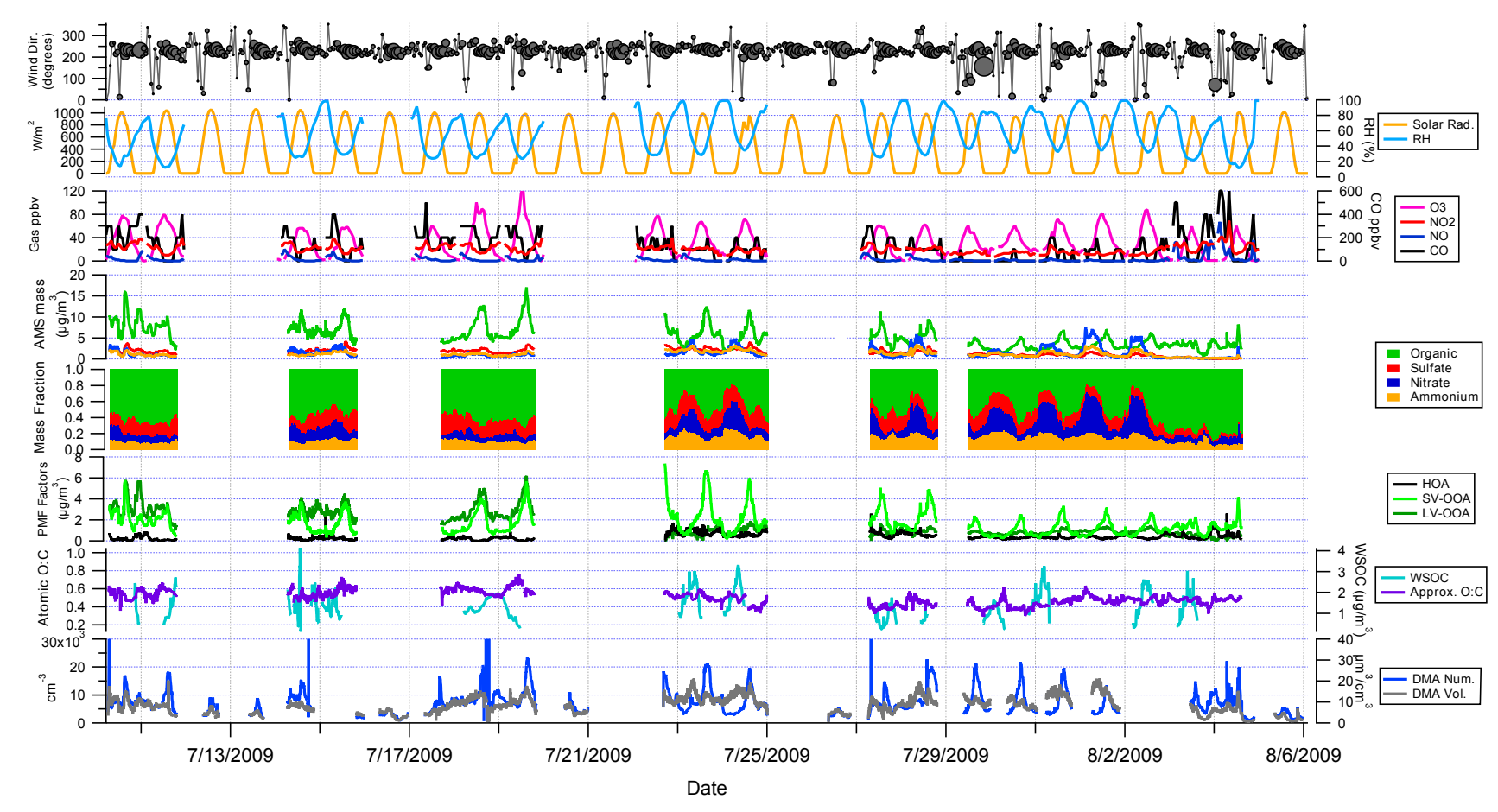

Fig. 1c. Regime III (wind direction marker size proportional to wind speed; $\max$ size $=20 \mathrm{~km} \mathrm{~h}^{-1}$ ).

particle concentration at the DMA-selected size with a water condensation particle counter (TSI Model 3831), and the remaining four channels consisting of parallel nafion humidification chambers (Perma Pure, LLP, Model MD-070-24FS4), followed by correspondingly humidified custom optical particle counters (OPCs). In the OPC sample volume, particles pass through a focused laser beam $(\lambda=532 \mathrm{~nm}$, World Star Technologies, Model TECGL-30) and scatter light in proportion to size $\left(D_{\mathrm{p}}\right)$ and refractive index (RI). Forwardscattered light is collected and focused on a photomultiplier tube, and the resulting electrical pulse is recorded by a high-speed data acquisition computer. An iterative data processing algorithm, based on laboratory calibrations with salts of known refractive indices, is used to determine the best fit on a solution surface relating electrical pulse height, size, and refractive index. The hygroscopic growth factor ( $\left.\mathrm{GF}=D_{\mathrm{p} \text {, wet }} / D_{\mathrm{p}, \mathrm{dry}}\right)$ is corrected for the RI change caused by particulate liquid water at elevated RH.

In the current study, the DASH-SP sampled for 4-h periods (07:00-11:00 and 15:00-19:00 LT). Hygroscopicity was measured at dry sizes corresponding to $D_{\mathrm{p}, \mathrm{em}}$ of 150,175 , 200, and $225 \mathrm{~nm}$. Multiple RH sensors in the nafion tubes and OPCs controlled RHs to dry $(\leq 8 \%), 74 \%, 85 \%$, and $92 \%$, with RH uncertainty of $1.5 \%$. Because calculated RI varied little during sampling periods, GF calculations were made with a single RI for each sampling period, representing the average RI calculated for the entire period. The error introduced by this assumption is small, as light scattering in the DASH is far more sensitive to size than RI. Overall uncertainty in GF calculations is calculated to be $4.5 \%$.

\section{Results and discussion}

\subsection{Atmospheric conditions}

Figure 1a-c is a compilation of meteorological data, as well as gas- and aerosol-phase composition for regimes I, II, and III, respectively. Wind speed and direction display distinct diurnal patterns, with stagnant or very light winds from the N/NE in the overnight to early morning hours (20:00-06:00 LT) changing direction to come from the W/SW shortly after sunrise (06:00-07:00 LT). Between 06:00 and 16:00 LT, wind speed increases from 3-4 $\mathrm{km} \mathrm{h}^{-1}$ to $13-15 \mathrm{~km} \mathrm{~h}^{-1}$ out of the W/SW before decreasing back to very light or stagnant out of the N/NE by 20:00 LT. One effect of these wind patterns is to allow local emissions to build up in the Los Angeles Basin during the nighttime and early morning hours, leading to significant carryover of aged aerosol in the background Los Angeles air, as proposed by (Blumenthal et al., 1978). When sea breezes develop, fresh emissions in source-rich areas are gradually transported from the Western Los Angeles Basin toward downwind areas in the E/NE. Situated $16 \mathrm{~km}$ from downtown Los Angeles, Pasadena can be considered as a receptor site that first receives transported pollution between 10:00 and 11:00 LT, after roughly $4-5 \mathrm{~h}$ of transport. During the afternoon hours 
(13:00-18:00 LT), the sampling site receives a steady influx of air from the W/SW with photochemical age of 1-2 h. There are no significant freeways or point sources of particulate pollution in close W/SW proximity to the sampling site, and so it is expected that air sampled during PACO is representative of transported urban air in Los Angeles. A major freeway with significant diesel and gasoline mobile sources is located $1.5 \mathrm{~km}$ to the north of the sampling site, and so overnight $\mathrm{N} / \mathrm{NE}$ winds may have periodically impacted the site with primary particulate emissions. Daytime variation in gas- and aerosol-phase composition is expected to result from three sources: (1) temporal changes in emissions from source-rich areas, (2) diurnal variations in the intensity of photochemistry, and (3) the age of transported pollution.

A clear diurnal trend is observed in RH and solar radiation, with RH increasing to near $100 \%$ on most nights and remaining at or near saturation until sunrise. The incidence of nighttime and morning marine cloudcover was common during regimes I and II, while regime III was typically drier, with clear nighttime skies more common. Periods of more significant marine layer influence are indicated by longer periods of saturated RH and more gradual decrease in RH (and slower increase in solar radiation) after sunrise. Regime I has been classified as "springtime meteorology" due to the impact of several low pressure systems in Southern California, bringing periodic drizzle and leading to several days of cloudcover and significantly diminished solar radiation (i.e. 6 to 12 June). Daytime RH rarely fell below $50 \%$ during regime I. Regime II exhibited the strongest summertime marine layer influence, with heavy cloudcover persisting until late morning (10:00 to 12:00 LT) nearly every day before making way for sunny, hazy afternoons with daytime RH between 25 and $40 \%$. Regime III observed the least marine layer influence, with many mornings of clear skies and daytime RH typically between 10 and $30 \%$. Despite differences in meteorology, the diurnal wind patterns described above were robust, with stagnant morning winds giving way to afternoon sea breezes and pollutant transport from the W/SW.

Gas-phase data give a sense of the atmospheric chemical environment during sampling. $\mathrm{O}_{3}$ exhibits a strong diurnal pattern correlated with solar radiation and serves as a tracer for photochemical activity. During periods of relatively dry atmospheric conditions, the $\mathrm{O}_{3}$ concentration peak increases in magnitude over subsequent days (see 17 to 19 July and 27 July to 2 August in regime III), suggesting that either pollutants accumulate or photochemical activity increases during periods of consistent, stable atmospheric conditions, resulting in photochemical episodes. $\mathrm{CO}$ and $\mathrm{NO}_{\mathrm{x}}$ display more random behavior, exhibiting periodic peaks in concentration indicative of plumes of fresher emissions.
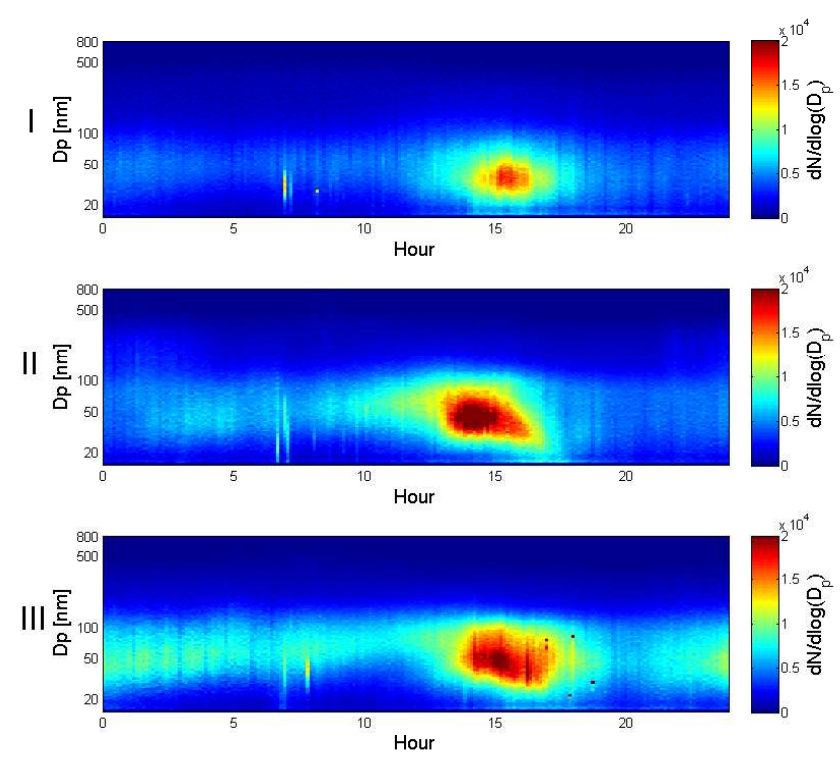

Fig. 2. Average diurnal DMA number concentrations $\left(\mathrm{cm}^{-3}\right)$ for regimes I, II, and III.

\subsection{Aerosol composition}

OC and EC mass concentrations, in addition to OC:EC ratios from representative days in each regime, are presented in Table 3. OC is higher in afternoon periods when compared with mornings in each regime $(27,18$, and $4 \%$ higher in regimes I, II, and III, respectively), while EC is lower during afternoons $(7,35$, and $22 \%$ lower in regimes I, II, and III, respectively). Further, OC:EC ratios are significantly higher during afternoon periods. These diurnal trends in $\mathrm{OC}$ are expected, given the importance of photochemical SOA production, and the percentage increase in OC mass between morning and afternoon periods is similar to that observed by the AMS $(15,17$, and $10 \%$ higher in regime I, II, and III, respectively). Discrepancies may arise due to the different size ranges measured by the AMS and filter sampling (upper limits of measurement are 1.0 and $2.5 \mu \mathrm{m}$ for the AMS and filters, respectively), in addition to potential volitalization of semivolatile organics relating to the thermo-optical OC/EC analysis technique. The modest increase in OC between morning and afternoon periods during the photochemically intense regime III may indicate that significant OC existed in the background aerosol during this period. The decrease in EC observed between morning and afternoon periods suggests that primary organics are a more significant portion of the Los Angeles aerosol in the mornings, and the relatively low concentrations of EC suggest that the dominant source of organic aerosol in Los Angeles is secondary.

DMA data are presented in panel 8 of Fig. 1a-c. Diurnal patterns are evident in both DMA volume and number in all regimes. DMA volume tends to reach a maximum in the midto-late morning (10:00, 11:00, 08:00 LT in regime I, II, and 
Table 3. OC/EC concentrations $\left(\mu \mathrm{g} \mathrm{m}^{-3}\right)$ for representative days from each regime.

\begin{tabular}{lcccccr}
\hline & OC & & EC & \multicolumn{3}{c}{ OC:EC } \\
\hline Regime & AM & PM & AM & PM & AM & PM \\
\hline I & $3.88 \pm 0.32$ & $4.92 \pm 1.18$ & $0.43 \pm 0.02$ & $0.40 \pm 0.27$ & 9.1 & 12.4 \\
II & $4.24 \pm 0.46$ & $5.01 \pm 1.62$ & $0.80 \pm 0.31$ & $0.52 \pm 0.40$ & 5.3 & 9.6 \\
III & $6.16 \pm 1.40$ & $6.41 \pm 1.44$ & $0.83 \pm 0.47$ & $0.65 \pm 0.22$ & 7.4 & 9.9 \\
\hline
\end{tabular}

III, respectively), when RH is still high and particles have presumably undergone cloud processing. The early maxima in regime III underscore the absence of significant marine layer influence persisting into the late morning. On average, DMA number concentration reaches a maximum between 14:00 and 15:00 LT during each regime, roughly $3 \mathrm{~h}$ after transported pollution is expected to first arrive at the sampling site (Fig. 2). This indicates that increases in fine particle mass at the PACO sampling site are not the result of transport alone, but also affected by photochemical production in transported, polluted air from source-rich areas. There was no significant difference in wind patterns between regimes, so the slightly earlier peak in DMA number in regime II suggests that marine moisture and aqueous-phase processes (most prevalent in regime II) may hasten secondary aerosol production. Figure 2 indicates that appreciable concentrations of fine particles $(<100 \mathrm{~nm})$ are present in late nights and early mornings (particularly in regimes II and III), possibly comprised of fresh emissions, nighttime-generated $\mathrm{NO}_{3}^{-}$, or fine particle carryover residing in a shallow mixed layer.

With the exception of a high-volume filter sampler located outdoors on the roof, instruments sampled from inlets connected to a main sampling line drawing in ambient air at a 161 per minute $\left(1 \mathrm{~min}^{-1}\right)$ laminar flow rate. Sample flow to each instrument was supplemented with pumps to be isokinetic with flow in the main sampling line, and sample lines were designed to draw from the center of flow through the main line. Ambient air was dried by nafion driers upstream of each instrument.

The third and fourth panels of Fig. 1a-c show time traces of bulk AMS aerosol mass concentration and mass fraction, respectively, while the sixth panel shows a time trace of approximate O:C ratio, based on Aiken et al. (2008), as well as WSOC concentration from the PILS-TOC (regime III). Organics dominated the aerosol sampled during PACO, and except for short episodes in regime I, the approximate $\mathrm{O}: \mathrm{C}$ ratio remained relatively constant during each regime $(0.44 \pm 0.08,0.55 \pm 0.05$, and $0.48 \pm 0.08$ during regimes I, II, and III, respectively). Organic aerosol in regime II appears to be more oxidized than I and III, suggesting that the marine moisture and presumed aqueous processing may enhance the rate of organic oxidation in Los Angeles. From bulk AMS time traces it is evident that organics increase in both magnitude and mass fraction each afternoon, particularly during the more photochemically active regimes II and III. It is noteworthy that there are no distinct trends in approximate $\mathrm{O}: \mathrm{C}$ between mornings and afternoons (morning approximate $\mathrm{O}: \mathrm{C}=0.44 \pm 0.08,0.54 \pm 0.08$, and $0.49 \pm 0.07$ for regimes I, II, and III, respectively, while afternoon approximate $\mathrm{O}: \mathrm{C}=0.44 \pm 0.08,0.53 \pm 0.06,0.50 \pm 0.08$ for regimes I, II, and III, respectively). This suggests that there is little change in overall oxidation state of Los Angeles aerosol, even on timescales of weeks. It is unlikely that all organics are uniformly oxidized at all times in Los Angeles, but rather that there exists a continuum of OA oxidation, with more reduced and more oxidized ends of that continuum maintaining a relatively constant ratio for extended periods of time.

Trends in aerosol mass fraction are presented in Fig. 4. Organics dominate the Los Angeles submicron aerosol, contributing 42,43 , and $55 \%$ of aerosol mass in regimes I, II, and III, respectively. Diurnal trends are evident in Fig. 4, with organic mass fraction increasing significantly from morning (07:00-11:00 LT) to midday (11:00-15:00 LT) to afternoon (15:00-19:00 LT) in each regime. Sulfate is a significant component in marine/moisture-influenced regimes I and II, and is a more minor component in regime III, suggesting that cloud processing and marine influence may be an important source of sulfate aerosol in Los Angeles. Nitrate contributes equal mass fractions in each regime, with a minimum in the afternoon and a maximum in the morning. Ammonium contributes a remarkably constant mass fraction to the aerosol, despite significantly less inorganic sulfate in regime III, suggesting an ammonium surplus for aerosol sampled in regime III. The significant peak in AMS masses during the early morning of 5 July (regime II) corresponds to a total submicron mass of over $200 \mu \mathrm{g} \mathrm{m}^{-3}$, and resulted from a myriad of fireworks displays in the area surrounding the sampling site. This plume has been removed from further analysis. Diurnal trends in bulk composition are highlighted in the top panel of Fig. 3. It is noteworthy that during the significantly marine-layer-impacted regime II, bulk organic, sulfate, nitrate, and ammonium masses are all enhanced. This is further evidence that aqueous processing associated with marine layer influence may be an important factor in generating aerosol mass in Los Angeles. Typically, organics increase in magnitude to a maximum near 14:00-15:00 LT in each 


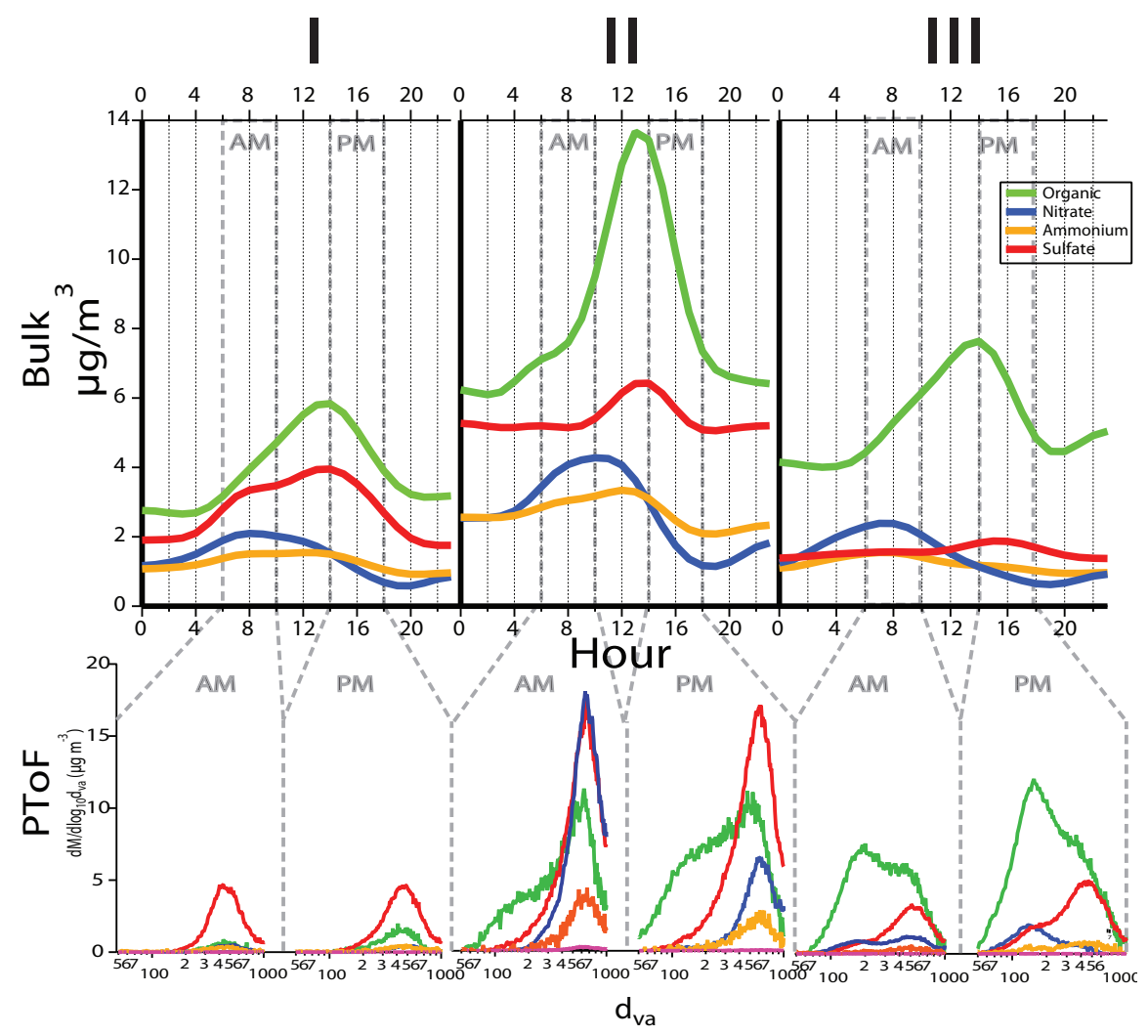

Fig. 3. Bulk AMS diurnal mass averages for regimes I, II, and III. Bottom panel shows size-resolved PToF AMS data for a representative morning and afternoon period in each regime, where morning $=$ 07:00-11:00 LT and afternoon = 15:00-19:00 LT.

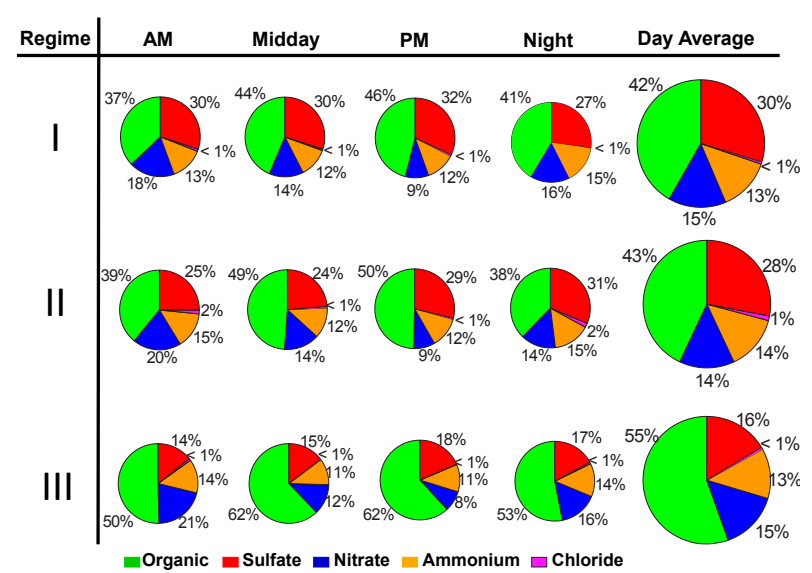

Fig. 4. AMS bulk mass fractions for AM (07:00-11:00 LT), midday (11:00-15:00 LT), PM (15:00-19:00 LT), and night (19:0007:00 LT) for regimes I, II, and III.

regime, corresponding to a maximum in ozone, solar radiation, and DMA number - evidence of photochemical SOA production. Sulfate exhibits slight enhancements during periods of peak photochemical activity in all three regimes, but as suggested by Kleeman et al. (1999), it appears to be predominantly a background marine species. Nitrate mass is highest in the nighttime and morning periods, likely resulting from ozone- $\mathrm{NO}_{\mathrm{x}}$ production of $\mathrm{HNO}_{3}$ at night and $\mathrm{HO}_{\mathrm{x}}-\mathrm{NO}_{\mathrm{x}}$ production of $\mathrm{HNO}_{3}$ after rush hour in the mornings. As mentioned in Sect. 3.1, there were periods of high $\mathrm{O}_{3}$ observed during PACO, and during several of these periods there also appeared to be significantly elevated levels of aerosol nitrate during nighttime sampling (e.g. 30 July to 3 August). Further, morning peaks in aerosol nitrate varied significantly in magnitude, suggesting that there may be significant variation in the amount of gas-phase $\mathrm{HNO}_{3}$ production from day to day.

Ammonium mass generally follows the combined trends of $\mathrm{SO}_{4}^{2-}$ and $\mathrm{NO}_{3}^{-}$, but appears to be in excess in regime III. Defining an ammonium ratio as:

(moles of $\mathrm{NH}_{4}^{+}$measured by AMS)

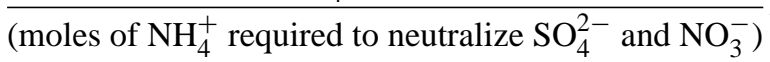

aerosol sampled in regimes I and II was found to be generally neutralized (average ammonium ratio $=0.96 \pm 0.21$ and $0.94 \pm 0.17$ for regimes I and II, respectively), while aerosol from regime III was characterized by significant ammonium excess $($ ammonium ratio $=1.28 \pm 0.30$ ). These 
results suggest that aerosol phase $\mathrm{NH}_{4} \mathrm{NO}_{3}$ was ammonialimited during regimes I and II, but ammonia may have been in excess during regime III. Investigating molar ratios of inorganic species, it is apparent that the role of $\mathrm{SO}_{4}^{2-}$ is significantly diminished in regime III, corresponding to the absence of marine layer influence. The ratio of $\mathrm{NO}_{3}^{-}$to $\mathrm{NH}_{4}^{+}$remains relatively constant across regimes $(0.32,0.29$, and 0.34 in regimes I, II, and III, respectively), while the ratio of $\mathrm{SO}_{4}^{2-}$ to $\mathrm{NH}_{4}^{+}$exhibits a marked decrease in regime III $(0.42,0.41$, and 0.24 in regimes I, II, and III, respectively). The AMS has difficulty distinguishing whether $\mathrm{NH}, \mathrm{NH}_{2}$, and $\mathrm{NH}_{3}^{+}(\mathrm{m} / \mathrm{z}$ 15,16 , and 17 , respectively) are contributed by inorganics or organic amines. One explanation for these trends is that ammonium may be chiefly inorganic during the moister, marinelayer-influenced regimes I and II, serving primarily to neutralize $\mathrm{SO}_{4}^{2-}$ and $\mathrm{NO}_{3}^{-}$, while there may be an influence from organic amines in the absence of marine layer influence during regime III. While particulate amines have been observed in the particle phase, it is unclear why they would appear to be more prevalent in regime III, as amines are typically associated with cooler, moister environments. Another explanation is that the "excess" $\mathrm{NH}_{4}^{+}$may be associated with organic anions. An enhancement in acidic organic species, which would not be unexpected in a hot, dry, photochemically active regime, may lead to a corresponding enhancement in neutralizing $\mathrm{NH}_{4}^{+}$. Since the AMS does not specifically quantify organic anions, such an enhancement in both organic acids and associated $\mathrm{NH}_{4}^{+}$would lead to an increased ammonium ratio.

The bottom panel of Fig. 3 shows size-resolved PToFAMS composition for a representative morning and afternoon period in each regime, with 9 June, 19 June, and 19 July representing regimes I, II, and III, respectively. Size-resolved data indicate that aerosol in regime I is typically internallymixed, with the mode centered at $\sim 400-500 \mathrm{~nm}$. Afternoon PToF data from regime I indicate that photochemical organic production typically results in organics condensing on existing accumulation mode aerosol. Regime II is characterized by significantly higher aerosol mass and more complex size distributions. While there is a significant internally-mixed accumulation mode present and centered at $\sim 600-700 \mathrm{~nm}$, there is also significant aerosol mass at sizes smaller than $300 \mathrm{~nm}$ in both morning and afternoon sampling periods, though the mass at smaller sizes does not comprise a distinct mode. Afternoon PToF data from regime II indicate that a fine mode appears coincident with photochemistry, suggesting that fine mode aerosol is predominately comprised of secondary species. Nitrate, sulfate, and ammonium are generally confined to accumulation mode aerosol in regime II. Regime III PToF data reveal an aerosol that is dominated by organics at all sizes and is distinctly bimodal. In addition to an internally mixed accumulation mode centered at $\sim 500-600 \mathrm{~nm}$, distributions from regime III also reveal a significant fine mode centered at $\sim 100-200 \mathrm{~nm}$. The accumulation mode tends to be comprised of sulfate, nitrate, and ammonium (in addition to organics) in the morning periods, with less nitrate in afternoons. Afternoon PToF data from regime III, like those from regime II, reveal fine-mode aerosol growth resulting from production of secondary organic species. Numerous studies have shown that the critical species for new particle formation in the atmosphere is $\mathrm{H}_{2} \mathrm{SO}_{4}$. The extent to which the observed fine mode aerosol might have originated from the nucleation of gasphase species during PACO is unclear. However, given the relatively large amount of pre-existing aerosol surface area, as well as the relatively low concentration of $\mathrm{SO}_{2}$, the precursor to $\mathrm{H}_{2} \mathrm{SO}_{4}$, it is unlikely that new particle formation by nucleation is an important process in Los Angeles. Instead, the growth of fine-mode organics is proposed to occur by condensation of SOA on existing ultrafine primary aerosol. This tentative conclusion is contrasted with results from Pittsburgh, in which Stanier et al. (2004) found new particle formation to be an important process, strongly correlated with $\mathrm{SO}_{2}$ concentrations. Whether condensing on nucleated sulfate or existing ultrafine primary aerosol, growth of fine mode particles in Los Angeles is predominantly due to SOA.

Figure 5 shows the hourly average for WSOC mass (top panel, representing WSOC organic mass) and \% of AMS organic accounted for by WSOC (bottom panel) for regime III. A factor of 1.8 was used to convert water soluble carbon (WSOC) mass to water soluble organic mass (WSOM), within the range of factors presented by Turpin and Lim (2001), and matching the factor used by Docherty et al. (2008) for aerosol in the Los Angeles Basin. Averaged hourly data reveal a trend in WSOM, increasing from a minimum in the late evening and early morning to a maximum at 15:00 LT, corresponding to maxima in $\mathrm{O}_{3}$ concentration, solar radiation, AMS organic, and DMA number concentration. This suggests that photochemical production of SOA in air transported from source-rich areas is a significant source of WSOM in the Los Angeles Basin. While there is a diurnal trend in WSOM, the fraction of AMS organic accounted for by WSOM is relatively constant at $0.44 \pm 0.16$ during regime III, with a slight enhancement between 15:00 and 19:00 LT. This suggests that while significant WSOM is photochemically generated during the course of a day, water soluble organics comprise a relatively constant percentage of organic aerosol in Los Angeles. WSOC has been found to correlate well with oxidation state of organic aerosol (e.g., Kondo et al., 2007). Given the relatively constant approximate $\mathrm{O}: \mathrm{C}$ ratio observed in regime III and steady afternoon influx of polluted air on the order of 1-2 $\mathrm{h}$ old, the constant WSOM:AMS organic ratio is not unexpected.

\subsection{PMF results}

AMS data from PACO were combined into a single continuous dataset for analysis by the PMF method. PMF produced several non-unique solutions that were compared with known 


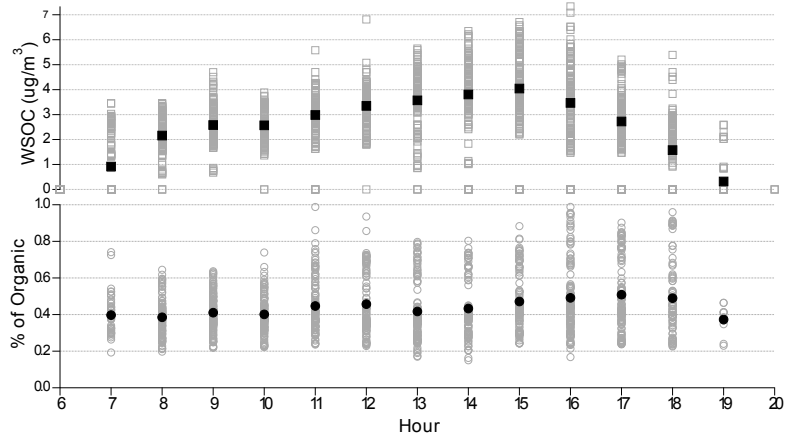

Fig. 5. WSOC magnitude (squares) and \% of AMS organic (circles). Black markers represent the average over regime III.

mass spectra and external time traces in order to choose final solutions. Figure 6 presents a summary of PMF factors, while panel 6 of Fig. 1a-c represents time traces for PMF factors for regimes I, II, and III, respectively. Details of the PMF method and solution selection are presented in Appendix A.

Three factors were resolved from the PMF method, and comparisons with previously published spectra indicate that they correspond to a hydrocarbon-like organic aerosol (HOA) and semivolatile- and low-volatility-oxygenated organic aerosol (SV-OOA and LV-OOA, respectively). PMF analysis was also performed on each regime separately, to determine the sensitivity of solutions to the assumption that $\mathrm{OA}$ is comprised of factors with constant mass spectra. In each case (HOA, SV-OOA, and LV-OOA), the factors resolved in the bulk analysis displayed a high degree of correlation (Pearson's R generally on the order of 0.94-0.99 for LV-OOA, SV-OOA, and HOA) with those resolved in analysis of individual regimes. The HOA factor is closely correlated with previously published spectra from periods dominated by reduced, primary organics (Zhang et al., 2005; Lanz et al., 2007; Ulbrich et al., 2009), and has significant signal at $m / z, 41$ and 57. The LV-OOA factor is closely correlated with previously-published OOA-1 factors and OOA-like factors observed in highly oxidizing environments (Zhang et al., 2005; Lanz et al., 2007; Ulbrich et al., 2009; Alfarra et al., 2004). The SV-OOA factor is also correlated with previously-published OOA factors, but has a higher degree of correlation with previously-published factors expected to represent less-aged, less-oxidized, semivolatile oxygenated organic aerosol, or SV-OOA (Zhang et al., 2005; Lanz et al., 2007; Ulbrich et al., 2009; Bahreini et al., 2005; Alfarra et al., 2004). The LV-OOA factor has a larger ratio of $\mathrm{m} / \mathrm{z} 44$ to $\mathrm{m} / \mathrm{z}$ 43 , an indication of a more aged, oxidized organic component ( $\mathrm{Ng}$ et al., 2010). The SV-OOA factor, on the other hand, has a smaller $m / z 44$ to $m / z 43$ ratio. PACO PMF factors correlated closely with "standard" HOA, SV-OOA, and LV-OOA factors reported by $\mathrm{Ng}$ et al. (2011), based on an average of results from 15 sites.
As seen in Fig. 1a-c, the HOA factor has the character of a periodic plume source, with low background concentrations punctuated by sudden, significant increases in concentration that remain high for several hours at a time. These increases in HOA concentration occurred primarily during regime I and are typically correlated with or just following peaks in $\mathrm{CO}$ concentration (panel 3 in Fig. 1a-c), though the low time- and concentration-resolution of $\mathrm{CO}$ measurements made statistical analysis difficult. HOA is typically associated with primary organic aerosol (POA) (e.g., Ulbrich et al., 2009; Ng et al., 2010), and the only significant local source of POA is expected to be the 210 freeway, $1.5 \mathrm{~km}$ north of the sampling site. There appears to be a trend of HOA plumes coinciding with or immediately following periods of light winds out of the N, which suggests that the HOA-like factor may represent primary freeway emissions. It is unclear why this HOA factor does not appear during every period of light winds out of the N. Low correlation between the HOA factor and ozone $(\mathrm{Pr}=0.39)$ suggests that HOA production is not a photochemical process, and low correlations with inorganic AMS traces $(\operatorname{Pr}=0.18,0.15,0.21$, and 0.02 for sulfate, nitrate, ammonium, and chloride, respectively) suggest that HOA production is independent of formation of inorganic aerosol, and that HOA may comprise an externally mixed mode, separate from the accumulation mode aerosol that is typically comprised of inorganic constituents.

The more dominant LV-OOA factor is most significantly correlated with inorganic AMS traces $(\operatorname{Pr}=0.75,0.46,0.65$, and 0.46 for sulfate, nitrate, ammonium, and chloride, respectively). As discussed in Sect. 3.2, inorganics are most prevalent in accumulation mode aerosol (rather than fine mode), and their loadings appear to be associated with significant marine layer influence in the Los Angeles Basin (e.g., regimes I and II). The high degree of correlation between $\mathrm{LV}$ OOA and inorganic constituents suggests that the LV-OOA factor represents an organic component that typically resides in accumulation mode aerosol and may be associated with marine layer/cloud processing influence. The correlation between LV-OOA and ozone is relatively low $(\mathrm{Pr}=0.39)$, indicative of an aged background organic species, as opposed to a rapidly-produced photochemical product that exhibits a distinct diurnal trend. Examining time traces for LV-OOA in Fig. 1a-c reveals that the LV-OOA factor exhibits relatively high background levels in the mornings and at night, while periodically showing moderate increases in magnitude during midday periods of photochemistry. These periodic photochemical trends in LV-OOA correspond to periods of intense photochemistry (e.g., 18-19 July), characterized by midday ozone concentrations near $80-100 \mathrm{ppb}$. This suggests that while LV-OOA appears to be the major constituent of the aged background aerosol discussed in Sect. 3.2, it can be photochemically produced on relatively short timescales during periods of intense photochemical activity. Its strong correlation with $\mathrm{SO}_{4}^{2-}$, consistent presence during humid overnight and morning hours, coincidence 

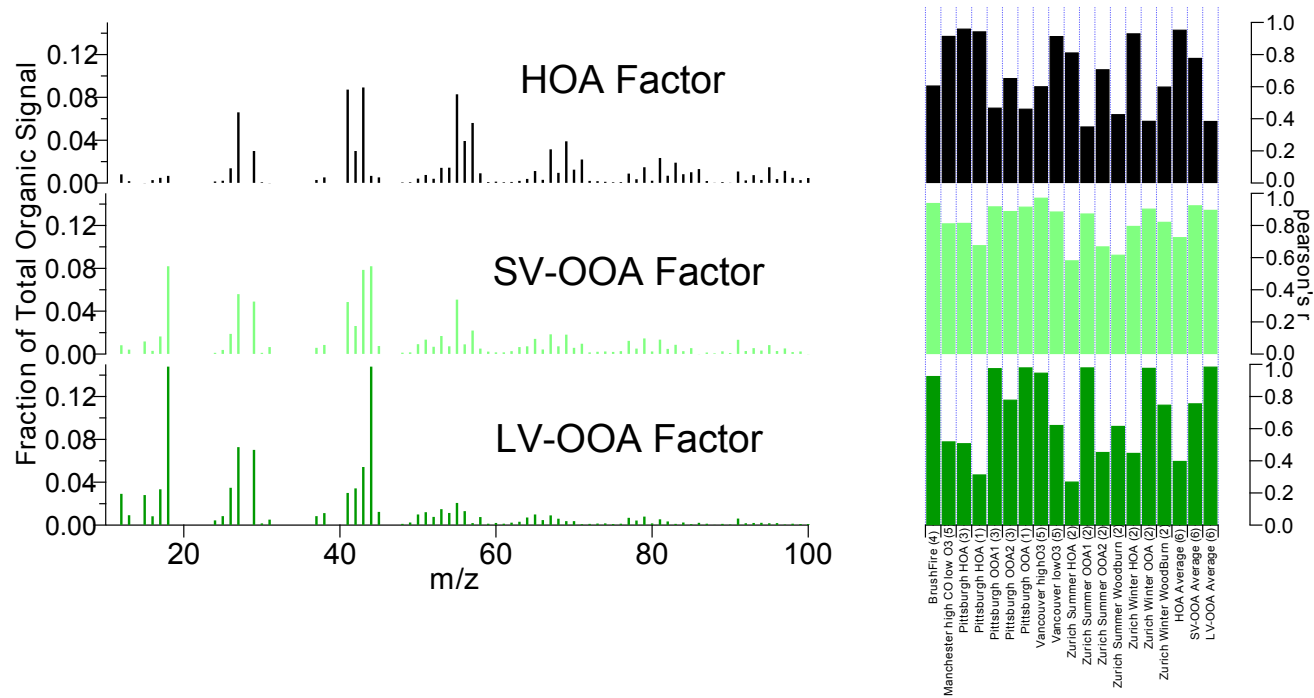

Fig. 6. Mass spectra for the three factors identified in PMF analysis (HOA, SV-OOA, and LV-OOA; left) and Pearson's R correlations of those solution mass spectra with previously reported mass spectra (1, 2, 3, 4, 5, 6: Zhang et al., 2005; Lanz et al., 2007; Ulbrich et al., 2009; Bahreini et al., 2005; Alfarra et al., 2004; $\mathrm{Ng}$ et al., 2011, respectively).

with accumulation mode aerosol, and greater prevalence in moisture-impacted regimes I and II suggest that there may be significant aqueous processing sources for LV-OOA in Los Angeles.

Figure 1a-c show a regular diurnal trend in SV-OOA, with overnight minima increasing to maximum concentrations daily at approximately 14:00-15:00 LT, correlating with maxima in solar radiation, AMS organic, and DMA number concentration. The SV-OOA factor exhibits a reasonable degree of correlation with ozone ( $\mathrm{Pr}=0.53)$, suggesting that semivolatile organics are products of short-timescale photochemical oxidation of VOCs. Correlations with inorganic traces are lower than those for LV-OOA $(\mathrm{Pr}=0.42,0.31$, 0.45 , and 0.19 for sulfate, nitrate, ammonium, and chloride, respectively). As discussed in Sect. 3.2, aerosol size distributions exhibit significant enhancements in fine mode aerosol in afternoon periods, with the fine mode comprised almost entirely of organics (particularly in regimes II and III). Further, SV-OOA correlates strongly with DMA number concentration $(\mathrm{Pr}=0.62$, vs. 0.00 and 0.33 for HOA and LV-OOA, respectively). The regular, significant enhancements in SV-OOA during peak photochemical periods, high correlation with DMA number concentration combined with lower correlations with inorganics (which typically comprise accumulation mode aerosol), and the regular appearance of fine organic modes during afternoons suggests that the SVOOA factor is comprised of early-generation photochemical products that are chiefly responsible for the growth of finemode aerosol in the afternoons. Based on wind patterns discussed in Sect. 3.1, SV-OOA is proposed to consist of secondary organic products on the order of $1-2 \mathrm{~h}$ old, based on the transport time from source-rich areas near downtown to the sampling site.

Traditional PMF analysis correlates LV-OOA with sulfate, since $\mathrm{SO}_{4}^{2-}$ is essentially nonvolatile, and SV-OOA with nitrate since $\mathrm{NO}_{3}^{-}$is more volatile. These correlations are not necessarily based on mechanistic chemistry, but rather a similarity in volatilities. So there is no reason, on a fundamental chemical basis, that $\mathrm{NO}_{3}^{-}$should correlate better with SV-OOA than with LV-OOA. That is, the routes by which semivolatile organics and $\mathrm{NO}_{3}^{-}$reach the particle phase are distinctly different chemically. In the Los Angeles aerosol, these distinct pathways result in a relatively poor correlation between $\mathrm{SV}-\mathrm{OOA}$ and $\mathrm{NO}_{3}^{-}$. A better correlation between inorganics and LV-OOA suggests that the pathways by which they reach the aerosol phase are more similar than for SVOOA in transported Los Angeles Aerosol.

$\mathrm{Ng}$ et al. (2011) applied a simple method for making realtime estimates of OA components, based on an empirical scaling factor that relates HOA and OOA (further segregated as SV-OOA and LV-OOA) to signal at fragments $\mathrm{m} / \mathrm{z} 57$ and $m / z$ 44. HOA is estimated by $b \times\left(C_{57}-0.1 \times C_{44}\right)$, where $b$ for PACO was found to be 14.0, compared with 13.4 (range $=8.5-19.2$ ) for $\mathrm{Ng}$ et al. (2011). PACO OOA (combined SV-OOA and LV-OOA) is estimated by $c \times C_{44}$, where $c$ was found to be 8.1 for PACO, compared with 6.6 (range $=2.9-9.0$ ) by $\mathrm{Ng}$ et al. (2011). The PACO SVOOA and LV-OOA factors are estimated by $3.3 \times C_{44}$ and $4.8 \times C_{44}$, respectively.

Figure 7 shows the mass fraction of organic accounted for by each organic component during each regime. OA in Los Angeles is overwhelmingly oxidized in nature, with LV- and 
SV-OOA combined contributing 77, 92 , and $86 \%$ of OA during regimes I, II, and III, respectively. HOA contributed the largest fraction to OA during regime I, in large part due to episodically high HOA concentrations during May and early June. HOA is a minor factor during regimes II and III. SVOOA is a major constituent of OA during periods of photochemistry, with the hot, dry, photochemically intense regime III seeing the most significant contribution of SV-OOA to OA. LV-OOA dominates in regimes I and II, which were both periods of significant marine/moisture influence and cloud processing.

\subsection{Filter analysis}

PMF factors are mathematical solutions that return constant mass spectra that are combined linearly to describe variability in AMS data, and it is important to compare PMF results to physical, independent characterizations of OA. For PACO, UPLC-ESI-(+ and -)-MS analysis of high-volume filter samples was performed on 9 selected filters representing periods of high HOA, SV-OOA, and LV-OOA concentrations, in order to distinguish chemical profiles associated with the PMF factors. Periods distinguished as "high SVand LV-OOA" were chosen such that those species were the single, dominant component of OA. PACO filter sampling did not include any periods in which HOA was the isolated, dominant species, as periods distinguished as "high HOA" were also impacted by high background levels of LV-OOA.

Functional groups of interest in UPLC-ESI-(+)-TOF-MS analysis were basic nitrogen groups (i.e. amines, imines) as well as oxygen-containing moieties (i.e. carbonyls, alcohols, ethers). The complexity of the samples made complete speciation by this technique difficult, but it was possible to identify the majority of the base peaks. Non-oxygenated nitrogenous compounds likely to be amines were detected in significant concentrations and with some variety of carbon chainlength $(\mathrm{C} 8-\mathrm{C} 16)$ in the high $\mathrm{HOA}+\mathrm{LV}-\mathrm{OOA}$ periods, as well as during morning periods in which background LV-OOA dominated the organic fraction. This suggests that amines may be an important class of organic compounds in aged, background Los Angeles aerosol. The most prominent class of compounds in all filters was oxygenated organic species, with increased variety of oxygenated species during periods of significant photochemical organic production.

UPLC-ESI-(-)-TOF-MS offered better mass spectral resolution and more complete identification of base peaks than (+)-mode, allowing for more complete chemical profiles. $\mathrm{Ph}$ thalic acid is ubiquitous in appreciable quantities in the extractable fraction of Los Angeles OA. Phthalic acid has been identified as a significant product of poly-aromatic hydrocarbon (PAH) photochemistry (Kautzman et al., 2010), so this result suggests that PAHs may be a significant class of precursor VOCs to OA in Los Angeles. The high HOA + LVOOA samples were characterized by appreciable quantities of nitrogen- and sulfur-containing organics ( $>10 \%$ of the

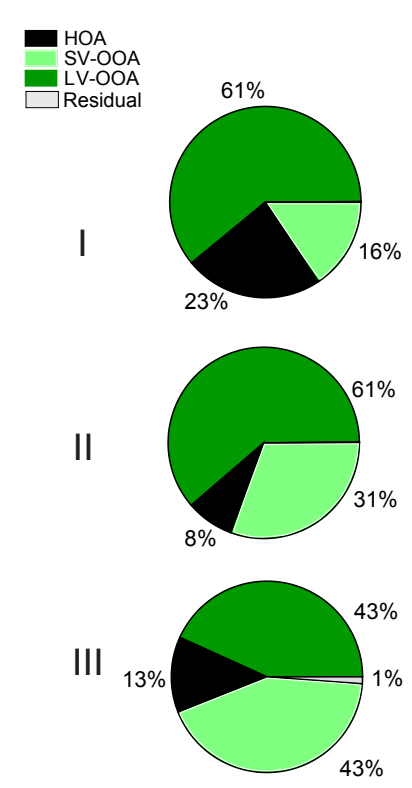

Fig. 7. Mass fraction of total organic accounted for by each PMF factor during regimes I, II, and III.

extractable, identifiable fraction), which is unique to periods in which both HOA and LV-OOA were high in magnitude. Carboxylic acids were significant during both SV- and LVOOA periods ( $>15 \%$ of extractable, identifiable fraction), though the carboxylic acids identified during SV-OOA periods tended to be longer-chain (C7-C10, as opposed to C4-C9 for LV-OOA periods). Additionally, aerosol in LV-OOA periods tended to have a more complex chemical profile, with no single class of compounds dominating the extractable fraction identified by UPLC. This suggests that while the SVand LV-OOA periods contain many of the same chemical compounds, LV-OOA tends to be characterized by smaller organic acids (higher O:C ratio), as well as a more complex profile of organonitrates, organosulfates, and oxidized acids. As explained in Ulbrich et al. (2009), aerosol partitioning with a bilinear PMF model is inherently limited in fitting a dynamic organic component. With a dataset as large as that represented by PACO, it is not unexpected that the organic component undergoes numerous and significant changes over the course of a single regime. Thus, two unique, constant mass spectra used to describe variability in a bilinear model may be more accurately viewed as two points on a continuum of volatility, rather than two distinct components of differing volatility. This hypothesis is supported by the commonality of compound classes identified by UPLC analysis for SV- and LV-OOA periods. The continuum of oxygenation is further illustrated in Fig. 8, a plot of $\mathrm{m} / \mathrm{z} 44$ $\left(\mathrm{CO}_{2}^{+}\right)$vs. $\mathrm{m} / \mathrm{z} 43$ (mostly $\mathrm{C}_{2} \mathrm{H}_{3} \mathrm{O}^{+}$) proposed by $\mathrm{Ng}$ et al. (2010) as a mass spectral diagnostic for the age of organic aerosol. It is hypothesized that LV-OOA components tend to have a higher ratio of $m / z, 44$ to $m / z 43$ and represent a lower- 


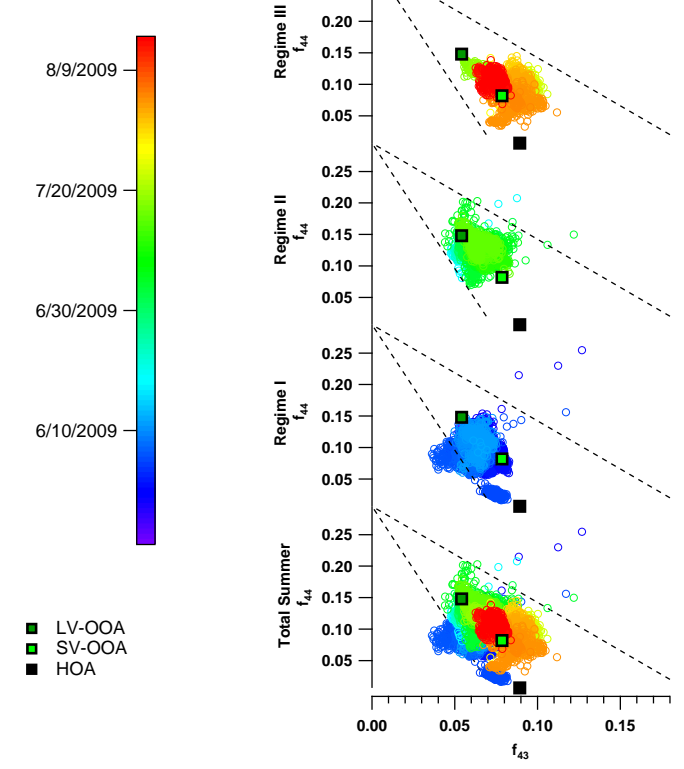

Fig. 8. $f_{44}$ vs. $f_{43}$ for PACO, with color scale corresponding to date. Square markers represent values for HOA, SV-OOA, and LVOOA factors identified in PACO.

volatility, more-aged organic component with a higher degree of oxidation. Results from PACO indicate that the organic component of Los Angeles aerosol produces a continuum of $f_{44}$ values during each regime and that the most aged organic fraction may actually be characterized by a predominance of longer-chain, oxidized monoacids, complex amines, and nitrate- and sulfate- containing organics. It is concluded that for the Los Angeles aerosol, a bilinear PMF model, with mass spectra assumed to be constant over an entire regime, is helpful in qualitatively assessing the degree of aging of the organic component, but represents a broad simplification of a dynamic organic fraction of aerosol.

\subsection{Hygroscopicity}

The intensity of scattered light is a strong function of particle diameter $\left(D_{\mathrm{p}}\right)$, and since aerosol water uptake largely determines particle size, it is a major variable determining the interaction of particles with radiation. Urban aerosol tends to be dominated by organic material, which is often hydrophobic, leading to overall growth factors (GFs, $D_{\mathrm{p} \text {, wet }} / D_{\mathrm{p} \text {,dry }}$ ) that are smaller than those for pure inorganic aerosol. At RH above the deliquescence RH of common inorganic aerosol constituents, the comparatively low hygroscopicity of organics tends to result in an inverse correlation between organic mass fraction and overall aerosol hygroscopicity (Shinozuka et al., 2009; Quinn et al., 2005; Hersey et al., 2009).

Because urban aerosol is, in part, an external mixture of organic and inorganic components, hygroscopic behavior is of- ten complex, with several GF modes observed (e.g., Cocker et al., 2001; Massling et al., 2005, 2009; Swietlicki et al., 2008; Meier et al., 2009; Tiitta et al., 2010; Rose et al., 2010). The optical sizing method utilized by the DASH-SP provides rapid measurements on timescales suitable for aircraft studies, but does not allow resolution of more than two modes (a nonhygroscopic and hygroscopic mode). During PACO, two modes were typically distinguishable: a nonhygroscopic mode $(1<\mathrm{GF}<1.15$ at $92 \% \mathrm{RH})$ identified during morning sampling ( $\leq 30 \%$ of aerosol), decreasing to very minor significance in the afternoon, in addition to a dominant hygroscopic mode that will be the focus of the rest of this section. This suggests that aerosol sampled in the morning included an appreciable fraction of nonhygroscopic particles, with afternoon photochemistry and SOA production resulting in an aerosol of more uniform, unimodal hygroscopicity. Since it was not possible to resolve multiple growth modes, GF data represent the overall subsaturated water uptake behavior for hygroscopic particles.

The DASH-SP measured GF at dry particle sizes of 150 , 175,200 , and $225 \mathrm{~nm}$. There was no statistically significant difference between GF at these dry sizes, and so data were averaged to give GFs representative for particles between 150 and $225 \mathrm{~nm}$ dry diameter. Particles sampled during morning periods (07:00-11:00 LT) were significantly more hygroscopic at 74 and $92 \%$ than those sampled during afternoon periods (15:00-19:00 LT); morning GF averaged 1.14 \pm 0.13 , $1.37 \pm 0.10$, and $1.97 \pm 0.45$ at 74,85 , and $92 \% \mathrm{RH}$, respectively, while afternoon GF averaged $1.06 \pm 0.04,1.37 \pm 0.07$, and $1.74 \pm 0.20$ at 74,85 , and $92 \% \mathrm{RH}$, respectively. Suppressed GF at 74 and $92 \%$ during afternoon sampling but constant GF at $85 \%$ suggests that the hygroscopic growth curve (GF vs. RH) for morning-sampled aerosol is one with a higher GF at lower RHs, combined with a steep ascending section at $\mathrm{RH}>85 \%$, suggestive of a predominantly inorganic aerosol with a small hygroscopic organic component and little nonhygroscopic aerosol.

These GF values are significantly higher than those measured during the 1987 SCAQS study in the eastern Los Angeles Basin (1.23 \pm 0.08 for $200 \mathrm{~nm}$ particles at $90 \pm 3 \% \mathrm{RH}$; Zhang and McMurray, 1993), and are more consistent with the most hygroscopic mode measured in Pasadena in 1999 (1.6 at $89 \%$ RH; Cocker et al., 2001).

Figure 9 shows GF at 74, 85, and $92 \%$ plotted against organic mass fraction (OMF), with markers colored by sampling date and time. PACO data show a clear trend of suppressed GF with increasing organic mass fraction $(\mathrm{Pr}=$ $-0.56,-0.78,-0.71$ for 74,85 , and $92 \%$, respectively). The lowest GFs and highest values of organic mass fraction occur late in PACO, during the dry and photochemically intense regime III characterized by significant photochemical production of SV-OOA.

An increasingly popular representation of aerosol hygroscopicity is the $\kappa$ parameter, developed by Petters and Kreidenweis (2007). As outlined in Shinozuka et al. (2009), one 


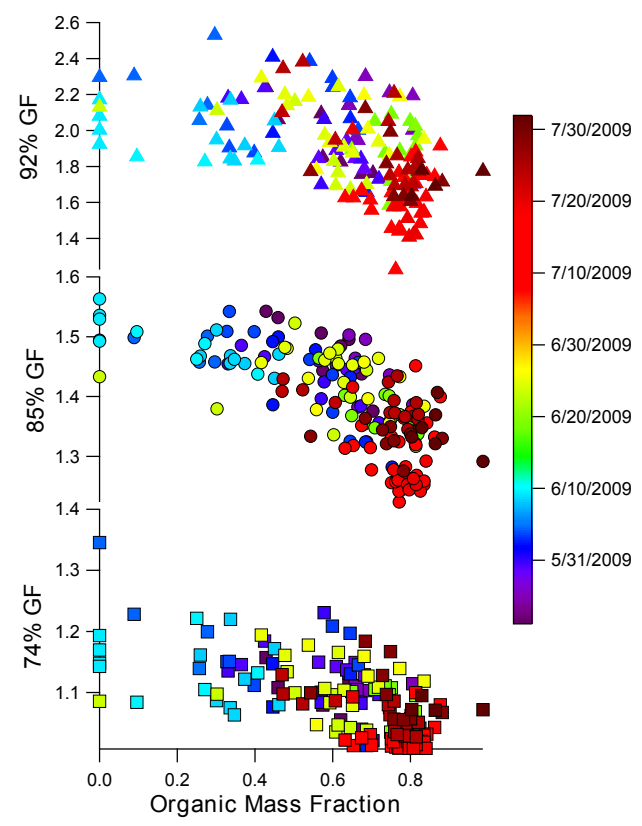

Fig. 9. GF at 74,85 , and $92 \% \mathrm{RH}$ plotted against organic mass fraction, with color scale corresponding to date.

can use size-resolved GF data at sub-saturated RH to solve the equation:

$S(D)=\frac{D^{3}-D_{\mathrm{d}}^{3}}{D^{3}-D_{\mathrm{d}}^{3}(1-\kappa)} \exp \left[\frac{4 \sigma M_{\mathrm{w}}}{R T \rho_{\mathrm{w}} D}\right]$

for $\kappa$, where $S$ is the saturation ratio over an aqueous droplet (0.74, 0.85 , or 0.92$), D$ and $D_{\mathrm{d}}$ are the humidified and dry diameters, respectively, $\sigma$ is the surface tension at the interface of air and pure water $\left(0.072 \mathrm{~J} \mathrm{~m}^{-2}\right), M_{\mathrm{w}}$ is the molecular weight of water $\left(18 \mathrm{~g} \mathrm{~mol}^{-1}\right), R$ is the gas constant $(8.3$ $\left.\mathrm{J} \mathrm{mol}^{-1} \mathrm{~K}^{-1}\right), T$ is the temperature $(298 \mathrm{~K})$, and $\rho_{\mathrm{w}}$ is the density of water $\left(1 \mathrm{~g} \mathrm{~cm}^{-3}\right)$. Because the effect of organics on surface tension is not explicitly accounted for in this model, the $\kappa$ here may be regarded an "effective hygroscopicity parameter", which includes both solute-induced water activity changes and surface tension effects (Petters and Kreidenweis, 2007; Rose et al., 2010).

Using the calculated $\kappa$ values, one may estimate critical dry diameter $\left(D_{\mathrm{d}}\right)$, or the diameter above which aerosol particles activate as cloud consenation nuclei $(\mathrm{CCN})$ at a given saturation ratio $(S)$, using the following equations:

$\kappa=\frac{4 A^{3}}{27 D_{\mathrm{d}}^{3} \ln ^{2} S}$

where:

$A=\frac{4 \sigma M_{\mathrm{w}}}{R T \rho_{\mathrm{W}}}$
Following Shinozuka et al. (2009) and assuming a supersaturation $\left(S_{\mathrm{c}}\right)$ of $0.2 \%$, the relationship between $\kappa$ and $D_{\mathrm{d}}$ becomes:

$D_{\mathrm{d}}=\kappa^{(-1 / 3)} \cdot 70 \mathrm{~nm}$

Values of $\kappa$ and critical dry diameter at $0.2 \%$ supersaturation were calculated based on GFs at $85 \%$ RH and dry particle diameter of $200 \mathrm{~nm}$. Uncertainties are estimated to be $25 \%$, based on sizing uncertainties in the DASH-SP and RH variation in the instrument (Sorooshian et al., 2008). Figure 10 shows $\kappa$ (left axis) and critical dry diameter (right axis; $D_{\mathrm{d}}$ ) plotted against organic mass fraction (OMF), colored by time and date. Kappa values range from 0.15 to 0.51 , with an average of $0.31 \pm 0.08$, while critical diameters ranged from 87 to $131 \mathrm{~nm}$, with an average of $105 \pm 10 \mathrm{~nm}$. As with GF data, there is a clear trend of decreasing $\kappa$ and increasing critical dry diameter with increasing organic mass fraction, with the lowest hygroscopicity and CCN activity occurring during regime III. Earlier periods characterized by more marine influence and higher RH exhibited more hygroscopic behavior. At low values of organic mass fraction, $\kappa$ approaches that of nitrate and sulfate salts (0.53-0.67), while approaching 0.1 at high organic fracion. Cubison et al. (2008) found that $\mathrm{CCN}$ concentrations in eastern Los Angeles were best modeled by treating organics (including the oxidized fraction) as nonhygroscopic. GF- and $\mathrm{CCN}$ - derived $\kappa$ values for hygroscopic organics range from 0.01 to 0.5 (Petters and Kreidenweis, 2007), with only the most hygroscopic organics (i.e. malonic acid) approaching the high end of that range. Results from PACO suggest that organics are moderately hygroscopic, with $\kappa$ values on the lower end of the range cited by Petters and Kreidenweis (2007).

Shinozuka et al. (2009) presented paramaterizations for calculating as a function of organic mass fraction for $100 \mathrm{~nm}$ $D_{\mathrm{p}}$, dry aerosol in Central Mexico and the North American West Coast $(\kappa=0.34-0.20 \cdot$ OMF and $\kappa=0.47-0.43 \cdot$ OMF, respectively), and these parameterizations are shown in Fig. 10. Overall, aerosol sampled during PACO are more hygroscopic at a given OMF than those presented in Shinozuka et al. (2009), and are parameterized as $\kappa=0.50-0.29$. OMF. This suggests that the organic fraction measured by Shinozuka et al. (2009) inhibits hygroscopicity significantly more than in Los Angeles. It is possible that the organics measured in Central Mexico and off the N. American West Coast exhibit more surface-active behavior, inhibiting hygroscopic activity, or that those organics are predominantly nonhygroscopic. In order to further investigate the hygroscopicity of organics, $\kappa$ calculations were combined with AMS data giving mass fractions of individual aerosol species in order to estimate a $\kappa$ value for organics, $\kappa_{\text {org }}$. If the overall hygroscopicity parameter, $\kappa$ is given by:

$\kappa=\sum_{i=1}^{n} \kappa_{i} \cdot \chi_{i}$, 


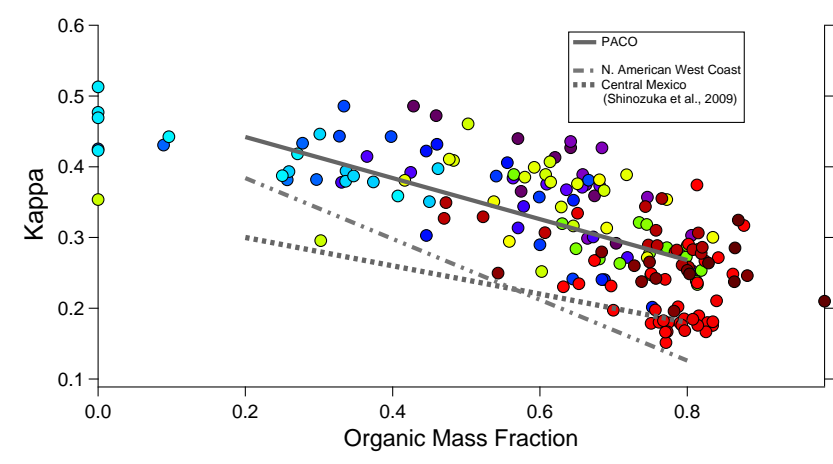

Fig. 10. $\kappa$ and critical dry diameter plotted against mass fraction organic, with color scale corresponding to date; lines represent empirical parameterizations from PACO, Central Mexico, and N. American West Coast.

where $n$ is the number of chemical constituents, $i$, with mole fraction $\chi_{i}$ and hygroscopicity parameter $\kappa_{i}$, then the organic hygroscopicity parameter, $\kappa_{\text {org }}$ can be estimated by:

$\kappa_{\mathrm{org}}=\frac{\kappa-\sum_{i=1}^{n_{\text {inorg }}} \kappa_{i} \cdot \chi_{i}}{\chi_{\mathrm{org}}}$,

where $n_{\text {inorg }}$ is the number of inorganic constituents, $i$, with hygroscopicity parameter $\kappa_{i}$ and mole fraction $\chi_{i}$, and $\chi_{\text {org }}$ is the mole fraction of organics in the aerosol. Previous publications have assumed $\kappa_{\text {org }}$ of 0.1 for "hygroscopic" organics, and 0 for "nonhygroscopic" organics (Dusek et al., 2010; Wang et al., 2010; Wex et al. , 2010). Assuming $\kappa_{i}$ for inorganics to be 0.6 and $\kappa_{i}$ for sea salt to be 1.3 (Wex et al. , 2010), Eq. (7) gives $\kappa_{\text {org }}$ of 0.16 for urban background aerosol transported to the PACO sampling site. Assuming $\kappa_{i}$ for inorganics to be 0.7 (Dusek et al., 2010) gives $\kappa_{\text {org }}$ of 0.12 . Taking a median $\kappa_{\text {org }}$ of 0.14 , it is clear that the organics measured during PACO are significantly more hygroscopic than those previously measured in urban areas. This is not unexpected, given the consistently high $\mathrm{O}: \mathrm{C}$ ratios of organics and the dominance of SV-OOA and LV-OOA during all three regimes of PACO. Further, the PACO sampling site is relatively free from the influence of local sources of primary aerosol, which would have the effect of reducing $\kappa_{\text {org }}$. Given that organics dominate aerosol in most urban areas, it is potentially significant to find that organics in an important urban center such as Los Angeles would have a value of $\kappa_{\text {org }}$ appreciably higher than previously calculated for urban aerosol.

\section{Conclusions}

A major ambient sampling experiment was conducted at a site in Pasadena, CA positioned to sample a constant afternoon influx of transported Los Angeles pollution with a photochemical age of roughly $1-2 \mathrm{~h}$ and generally free from the influence of local point sources. Sampling spanned 4 months during the summer of 2009, and was characterized by three distinct meteorological regimes: a "springtime" period characterized by clean conditions coincident with low pressure systems (regime I), a typical early-summer period characterized by significant morning marine layer followed by warm, photochemically active afternoons (regime II), and a latesummer period characterized by little marine layer influence, hot and dry conditions, and elevated photochemical activity (regime III).

Chemical analysis of aerosol revealed that OC dominates particulate carbon in Los Angeles (OC:EC average of 8.04), and is enhanced relative to $\mathrm{EC}$ by an average of $47 \%$ in the afternoon, suggesting significant SOA production. High RH during marine-layer-influenced morning sampling periods resulted in aqueous processing of aerosol particles and high aerosol volume, while drier afternoon periods saw increased aerosol number and volume due to SOA production. Maxima in aerosol volume occured in the mid-late morning, reflecting a balance between $\mathrm{RH}-$ induced hygroscopic growth and SOA production. Maxima in aerosol number tended to occur near 14:00-15:00 LT, indicating that daytime photochemistry tended to generate a fine aerosol mode.

Organics are the most significant constituent of transported Los Angeles aerosol, contributing an average of 42 , 43 , and $55 \%$ of total submicron mass in regimes I, II, and III, respectively. Interestingly, there was no significant difference between morning and afternoon $\mathrm{O}: \mathrm{C}$ ratios, suggesting that the constant influx of $1-2 \mathrm{~h}$ old aerosol results in an overall organic oxidation state at the sampling site varying little despite significant SOA production. Regime II, characterized by significant morning marine layer influence followed by photochemically active afternoons, displayed significantly higher aerosol mass and 15-25\% higher average $\mathrm{O}: \mathrm{C}$ ratio, suggesting that aqueous processes may be important in the generation of secondary aerosol and OOA in Los Angeles. Afternoons during regime II and III are characterized by the appearance of a fine organic mode, suggesting that SOA contributes significantly to growth of fine particles. It is unclear whether these fine particles are the result of sulfate nucleation and subsequent SOA growth or SOA condensation on existing primary aerosol.

Water soluble organic mass (WSOM) reaches maxima near 14:00-15:00 LT, coincident with markers for photochemistry and suggesting significant SOA contribution to WSOM. Sulfate is predominantly an accumulation mode constituent, and its magnitude appears to depend on the degree of marine influence. Nitrate is similarly a predominantly accumulation mode species, reaching maxima after morning 
rush hour periods. Nighttime nitrate production is observed during periods in which maximum ozone levels indicated significant photochemical events. An ammonium ratio, defined as the moles of ammonium measured divided by the moles of ammonium required to neutralize sulfate and nitrate as $\left(\mathrm{NH}_{4}\right)_{2} \mathrm{SO}_{4}$ and $\mathrm{NH}_{4} \mathrm{NO}_{3}$, respectively, revealed that ammonia limits particulate $\left(\mathrm{NH}_{4}\right)_{2} \mathrm{SO}_{4}$ and $\mathrm{NH}_{4} \mathrm{NO}_{3}$ in regimes I and II. An ammonium ratio of $1.28 \pm 0.30$ in regime III suggests that ammonium was in excess and that organic amines may have been an important constituent of submicron aerosol during this hot, dry, photochemically intense sampling period with reduced marine sulfate influence.

PMF analysis of C-ToF-AMS data resolved three factors, corresponding to HOA, SV-OOA, and LV-OOA, and correlating well with the "standard" factors presented in $\mathrm{Ng}$ et al. (2011). The HOA factor appears to be a periodic plume source, generally appearing during or shortly after peaks in $\mathrm{CO}$ concentration. SV-OOA displays a strong diurnal pattern, correlating strongly with ozone and the appearance of a fine mode $(<100 \mathrm{~nm})$ in the aerosol size distribution, suggesting that these SOA products are generated on timescales of $1-2 \mathrm{~h}$ and tend to comprise a fine aerosol mode. LV-OOA is correlated with inorganic nitrate and sulfate and appears to be an aged carryover organic component that resides in accumulation mode aerosol, but may be generated on short timescales (1-2h) under extremely oxidizing conditions. Its prevalence during humid overnight and morning hours and enhanced importance in moisture-influenced regimes I and II suggest that there may be significant aqueous-phase sources for LV-OOA. Overall the organic fraction of Los Angeles aerosol is overwhelmingly oxidized, with LV- and SV-OOA contributing 77,92 , and $86 \%$ of OA in regimes I, II, and III, respectively.

Filter analysis by both $(+)$ and (-) mode UPLC-ESITOF-MS reveals a complex mixture of organic compounds dominated by oxygenated species. Long (C8-C16), nonoxygenated nitrogenous compounds likely to be amines are detected during periods impacted by high concentrations of background LV-OOA, suggesting that amines may be an important constituent of aged organic aerosol in Los Angeles. Phthalic acid represents a ubiquitous, appreciable fraction of extractable OA, suggesting that PAH photochemistry may be an important pathway for SOA production in Los Angeles. Organo-nitro-sulfate species are observed during periods when aerosol appears to be a mixture of aged background species and freshly emitted particles. Carboxylic acids appear to be major contributers to both SV- and LV-OOA, with LV-OOA tending to be associated with shorter (C4-C9) carboxylic acids and thereby higher O:C ratio.

The organic fraction of transported Los Angeles aerosol is dynamic and undergoes numerous and significant changes on timescales of days to weeks, despite exhibiting consistency in the overall degree of oxidation. Many compounds are common to periods identified as distinct by PMF analysis, and PACO data suggest that Los Angeles OA is best described as a complex, dynamic mixture of compounds that represent a continuum of oxidation. Thus, a bilinear PMF model that assumes constant mass spectra representative of classes of OA is a useful tool in qualitatively assessing the degree of OA aging and oxidation, but is a dramatic simplification of a complex organic fraction.

Finally, aerosol water uptake characteristics measured by the DASH-SP indicate that a bimodal distribution becomes more unimodal during periods of photochemical SOA production. The degree of hygroscopicity of the main hygroscopic mode is highly anti-correlated with organic mass fraction, as indicated by decreasing GF and $\kappa$, as well as increasing critical diameter with increased organic fraction. Values for $\kappa$ averaged $0.31 \pm 0.08$, approaching 0.5 at low OMF and 0.1 at high OMF. It appears that organics in Los Angeles inhibit hygroscopicity less than those measured in Central Mexico and off the N. American West Coast, potentially owing to less surface-active behavior or an organic fraction comprised of more water soluble species.

PACO represents the first major aerosol characterization in the Western Los Angeles Basin, and comparison with SOAR will help identify spatial variation in Los Angeles aerosol and determine the nature of aerosol evolution as it is transported from source-rich (western) to downwind (eastern) parts of Los Angeles. Further, its timing will serve to contextualize and compare forthcoming results from the CalNex field campaign, part of which involved ground sampling at the PACO site.

\section{Appendix A}

\section{PMF analysis}

PMF was initiated using 50 seed values, and then again using a range of fpeak values from -1 to 1 varying by 0.1 . Figures $\mathrm{A} 1$ and $\mathrm{A} 2$ show the $Q / Q_{\text {expected }}$ values for the different solutions. The PMF results were sorted by regime, number of factors, and seed (only where it caused the solution to vary) and compared to previously published mass spectra in the AMS online Spectral Database explained in Ulbrich et al. (2009). Table A1 shows Pearson's $r$ values comparing the PMF mass spectral profile solutions to existing mass spectra. Table A2 shows Pearson's $r$ values comparing the PMF time series solutions to gas phase tracers, AMS inorganic tracers, PILS tracers, and WSOC. Figure A3 shows total residuals of all masses over time for solutions with different factor numbers. Figure A4 shows the scaled residuals at each mass for the presented 3 factor solution. The 2 and 4 factor solution profiles and time series contributions are shown in Figs. A5a, b. 


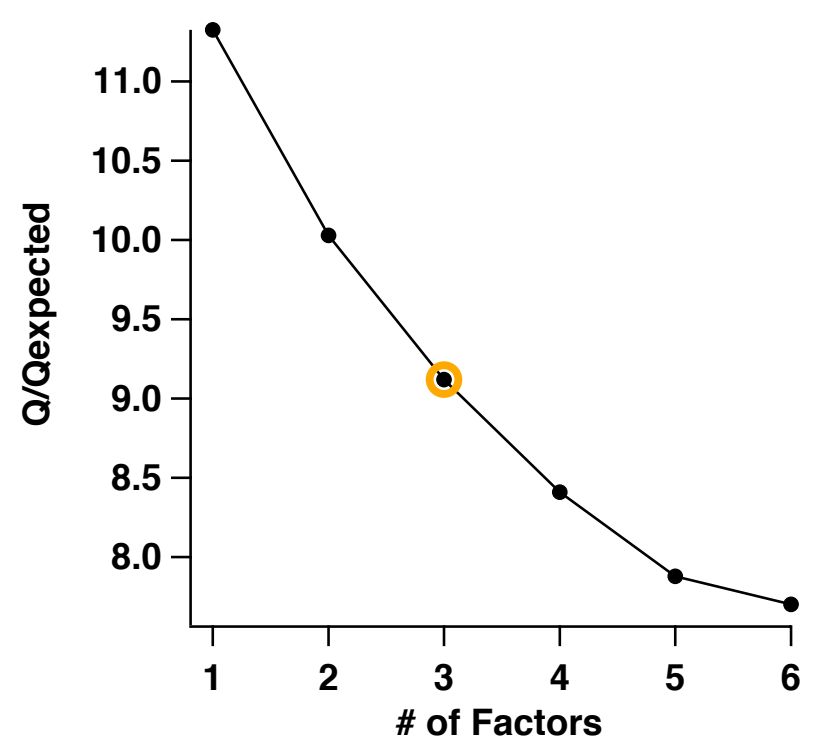

Fig. A1. $Q / Q_{\exp }$ values for varying number of factors ( $p$ values). The circled marker is the presented solution.

The difference in the total residuals was noticeable between the 1 and 2 factor solution and the 2 and 3 factor solution, but negligible between the 3 and 4 factor solution. In the 2 factor solution there is evidence of an HOA-like factor and OOA-like factor from the mass spectral comparison, but the when compared to the 3 factor solution, the time series correlations with AMS inorganic and certain gas phase tracers is improved. In the 3 factor case, 3 solutions were explored, and were representative of the 50 possible solutions from the PMF results. Regarding the mass spectral profile, the seed ${ }^{-} 6$ solution was chosen since it has very strong correlations with the real mass spectra, and each of the profiles are least similar to one another (see the right hand side of Table A2) when compared to the two other 3 factor solutions. When considering the time series comparison, the seed $=6 \mathrm{LV}$-OOA like factor (factor 1) has the highest correlation with the AMS inorganic species. The p-ToF data suggests the organic profile of LV-OOA has similar particle size distributions to the AMS inorganic species (this was investigated in areas of known LV-OOA like factor and low SV-OOA like factor, since PMF was not performed on $\mathrm{pToF}$ data). When the afternoon sun reaches a maximum, there is another, smaller mode that is believed to be SV-OOA, without the strong inorganic signal. Also, the seed $=6 \mathrm{SV}$-OOA

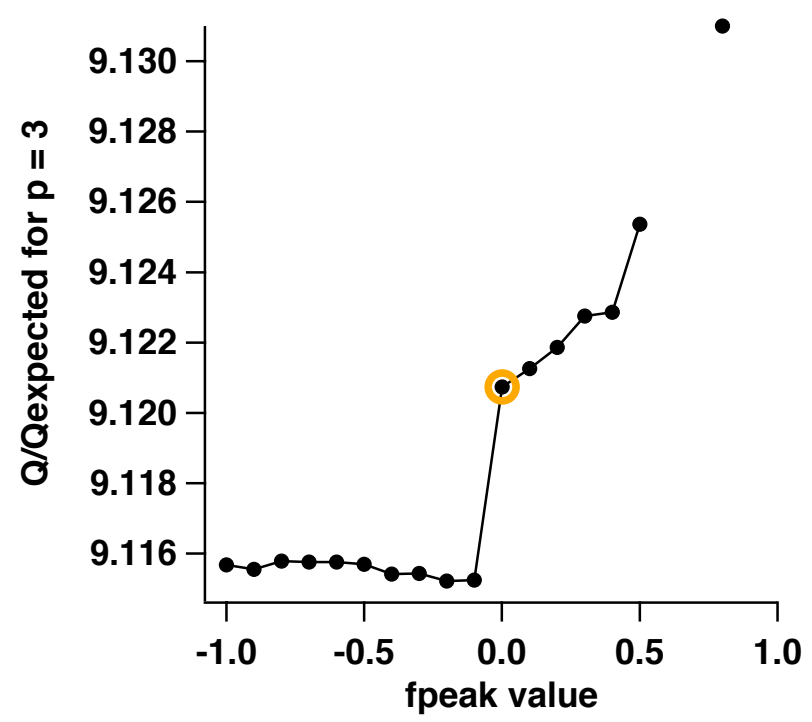

Fig. A2. $Q / Q_{\text {exp }}$ for varying fpeak values for $p=3$. The circled marker is the presented solution.

factor correlates best with ozone when compared to the two other solutions. The tracers for HOA were limited in this study since the resolution for the $\mathrm{CO}$ and $\mathrm{NO}_{\mathrm{x}}$ were poor and the $r$ values are very low. However, when comparing the seed $=6$ and seed $=1$ solutions, the correlations of the HOA-like factor to $\mathrm{CO}$ and $\mathrm{NO}_{\mathrm{x}}$ are slightly larger. Additionally, the HOA-like factor was compared to $\mathrm{m} / \mathrm{z} 57$, which is higher for the seed $=6$ solutions. The HOA correlations for the seed $=4$ solutions are slightly higher than in the seed $=1$ and seed $=6$ solutions, but this solution is not as strong mass spectrally, and when comparing the tracers for the two other factors. The four factor situation provided two different solutions, representative of the 50 seeds. In addition to the residuals not changing dramatically, in the mass spectral comparison, for both solutions, two of the factors have very similar $r$ values (factor 1 and 4 for seed 1 and factor 2 and 4 for seed 4). Also, the time series correlations are worse in the four factor solutions, when compared the the presented 3 factor solution. 
Table A1. Mass spectral comparison of several PMF solutions.

\begin{tabular}{|c|c|c|c|c|c|c|c|c|c|c|c|c|c|c|c|c|c|c|c|c|c|}
\hline \multicolumn{22}{|c|}{ Mass Spectra Comparison } \\
\hline 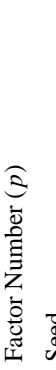 & & 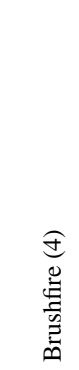 & 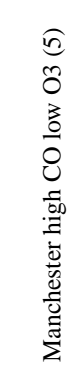 & 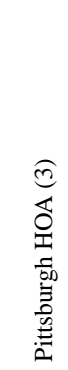 & 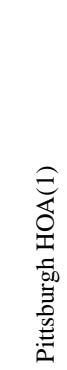 & 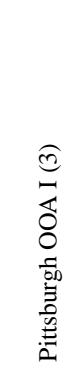 & $\begin{array}{l}\widehat{0} \\
= \\
\mathbb{0} \\
0 \\
0 \\
0 \\
\Xi \\
\Xi \\
0 \\
0 \\
0\end{array}$ & $\begin{array}{l}\widehat{\Xi} \\
\mathbb{0} \\
8 \\
0 \\
0 \\
\vdots \\
0 \\
0 \\
0 \\
0\end{array}$ & 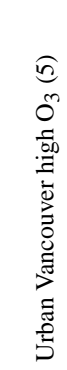 & 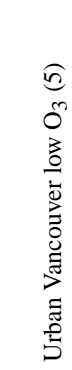 & 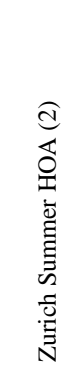 & 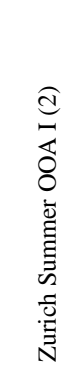 & 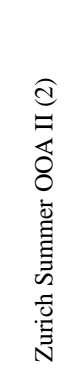 & 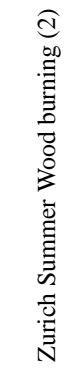 & 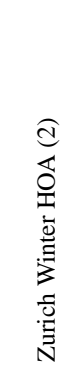 & 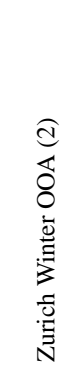 & 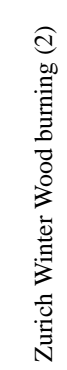 & $\begin{array}{l}\overline{\bar{g}} \\
\bar{u} \\
\text { I. }\end{array}$ & 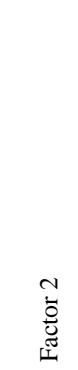 & 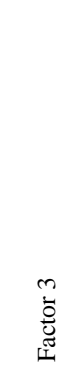 & 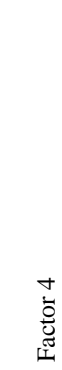 \\
\hline 1 & 1 & 0.96 & 0.68 & 0.68 & 0.51 & 0.97 & 0.85 & 0.97 & 0.99 & 0.77 & 0.44 & 0.95 & 0.58 & 0.64 & 0.66 & 0.97 & 0.81 & & & & \\
\hline 1 & 1 & 0.94 & 0.55 & 0.54 & 0.35 & 0.98 & 0.80 & 0.98 & 0.96 & 0.65 & 0.30 & 0.98 & 0.47 & 0.62 & 0.50 & 0.98 & 0.76 & & 0.64 & & \\
\hline 2 & 1 & 0.77 & 0.94 & 0.97 & 0.91 & 0.67 & 0.78 & 0.66 & 0.78 & 0.96 & 0.78 & 0.57 & 0.76 & 0.51 & 0.90 & 0.61 & 0.73 & 0.64 & & & \\
\hline 1 & 1 & 0.92 & 0.50 & 0.49 & 0.29 & 0.98 & 0.77 & 0.98 & 0.94 & 0.60 & 0.25 & 0.98 & 0.44 & 0.61 & 0.42 & 0.98 & 0.74 & & 0.56 & 0.56 & \\
\hline 2 & 1 & 0.74 & 0.91 & 0.95 & 0.88 & 0.63 & 0.73 & 0.62 & 0.74 & 0.93 & 0.76 & 0.53 & 0.71 & 0.51 & 0.88 & 0.56 & 0.69 & 0.56 & & 0.94 & \\
\hline 3 & 1 & 0.74 & 0.95 & 0.97 & 0.93 & 0.63 & 0.79 & 0.63 & 0.76 & 0.97 & 0.79 & 0.54 & 0.75 & 0.48 & 0.92 & 0.58 & 0.70 & 0.56 & 0.94 & & \\
\hline 1 & 4 & 0.93 & 0.66 & 0.66 & 0.49 & 0.93 & 0.79 & 0.93 & 0.93 & 0.73 & 0.42 & 0.89 & 0.56 & 0.64 & 0.55 & 0.92 & 0.81 & & 0.92 & 0.57 & \\
\hline 2 & 4 & 0.92 & 0.51 & 0.50 & 0.30 & 0.98 & 0.78 & 0.98 & 0.95 & 0.61 & 0.26 & 0.99 & 0.45 & 0.61 & 0.44 & 0.98 & 0.74 & 0.92 & & 0.39 & \\
\hline 3 & 4 & 0.59 & 0.93 & 0.97 & 0.96 & 0.46 & 0.67 & 0.45 & 0.61 & 0.93 & 0.83 & 0.35 & 0.72 & 0.39 & 0.95 & 0.38 & 0.58 & 0.57 & 0.39 & & \\
\hline 1 & 6 & 0.93 & 0.52 & 0.51 & 0.32 & 0.98 & 0.78 & 0.98 & 0.95 & 0.62 & 0.27 & 0.98 & 0.46 & 0.62 & 0.45 & 0.98 & 0.75 & & 0.41 & 0.90 & \\
\hline 2 & 6 & 0.61 & 0.92 & 0.96 & 0.95 & 0.47 & 0.65 & 0.46 & 0.60 & 0.92 & 0.81 & 0.35 & 0.71 & 0.43 & 0.93 & 0.39 & 0.60 & 0.41 & & 0.73 & \\
\hline 3 & 6 & 0.94 & 0.81 & 0.82 & 0.68 & 0.92 & 0.89 & 0.92 & 0.97 & 0.89 & 0.58 & 0.88 & 0.67 & 0.62 & 0.80 & 0.91 & 0.82 & 0.90 & 0.73 & & \\
\hline 1 & 1 & 0.94 & 0.57 & 0.56 & 0.37 & 0.98 & 0.81 & 0.98 & 0.97 & 0.67 & 0.32 & 0.98 & 0.49 & 0.63 & 0.54 & 0.98 & 0.76 & & 0.89 & 0.49 & 0.93 \\
\hline 2 & 1 & 0.90 & 0.60 & 0.59 & 0.43 & 0.89 & 0.74 & 0.89 & 0.87 & 0.66 & 0.37 & 0.84 & 0.54 & 0.65 & 0.43 & 0.87 & 0.80 & 0.89 & & 0.53 & 0.86 \\
\hline 3 & 1 & 0.61 & 0.92 & 0.96 & 0.94 & 0.48 & 0.67 & 0.48 & 0.63 & 0.93 & 0.81 & 0.38 & 0.68 & 0.41 & 0.94 & 0.41 & 0.58 & 0.49 & 0.53 & & 0.56 \\
\hline 4 & 1 & 0.93 & 0.69 & 0.66 & 0.51 & 0.95 & 0.86 & 0.94 & 0.96 & 0.75 & 0.46 & 0.92 & 0.62 & 0.58 & 0.60 & 0.95 & 0.82 & 0.93 & 0.86 & 0.56 & \\
\hline 1 & 4 & 0.90 & 0.60 & 0.59 & 0.43 & 0.89 & 0.74 & 0.89 & 0.87 & 0.66 & 0.37 & 0.85 & 0.54 & 0.65 & 0.43 & 0.88 & 0.80 & & 0.89 & 0.53 & 0.87 \\
\hline 2 & 4 & 0.94 & 0.57 & 0.56 & 0.37 & 0.98 & 0.81 & 0.98 & 0.97 & 0.67 & 0.32 & 0.98 & 0.49 & 0.63 & 0.54 & 0.98 & 0.76 & 0.89 & & 0.49 & 0.93 \\
\hline 3 & 4 & 0.61 & 0.92 & 0.96 & 0.94 & 0.48 & 0.67 & 0.48 & 0.63 & 0.93 & 0.81 & 0.38 & 0.68 & 0.41 & 0.94 & 0.41 & 0.58 & 0.53 & 0.49 & & 0.56 \\
\hline 4 & 4 & 0.93 & 0.69 & 0.66 & 0.51 & 0.95 & 0.87 & 0.94 & 0.96 & 0.76 & 0.46 & 0.92 & 0.63 & 0.58 & 0.60 & 0.95 & 0.82 & 0.87 & 0.93 & 0.56 & \\
\hline
\end{tabular}

(1) Zhang, et al., 2005; (2) Lanz et al., 2007; (3) Ulbrich, et al., 2009; (4) Bahreini et al., 2005; (5) Alfarra et al., 2004

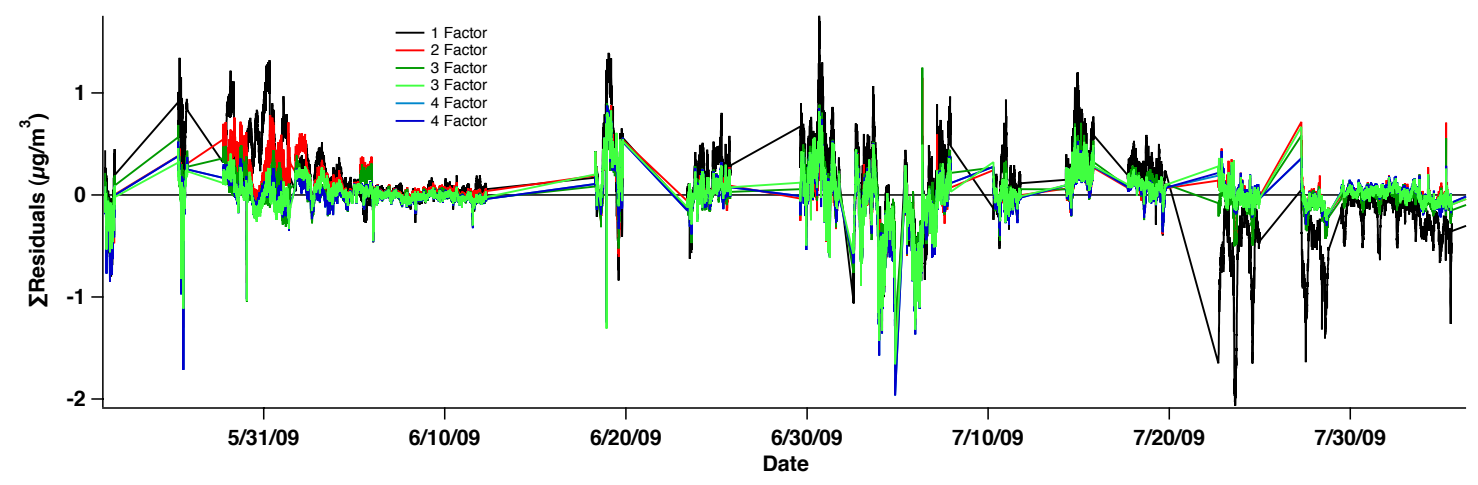

Fig. A3. Sum of the residuals for 1, 2, 3, and 4 factor solutions. 
Table A2. Time series comparison of several PMF solutions.

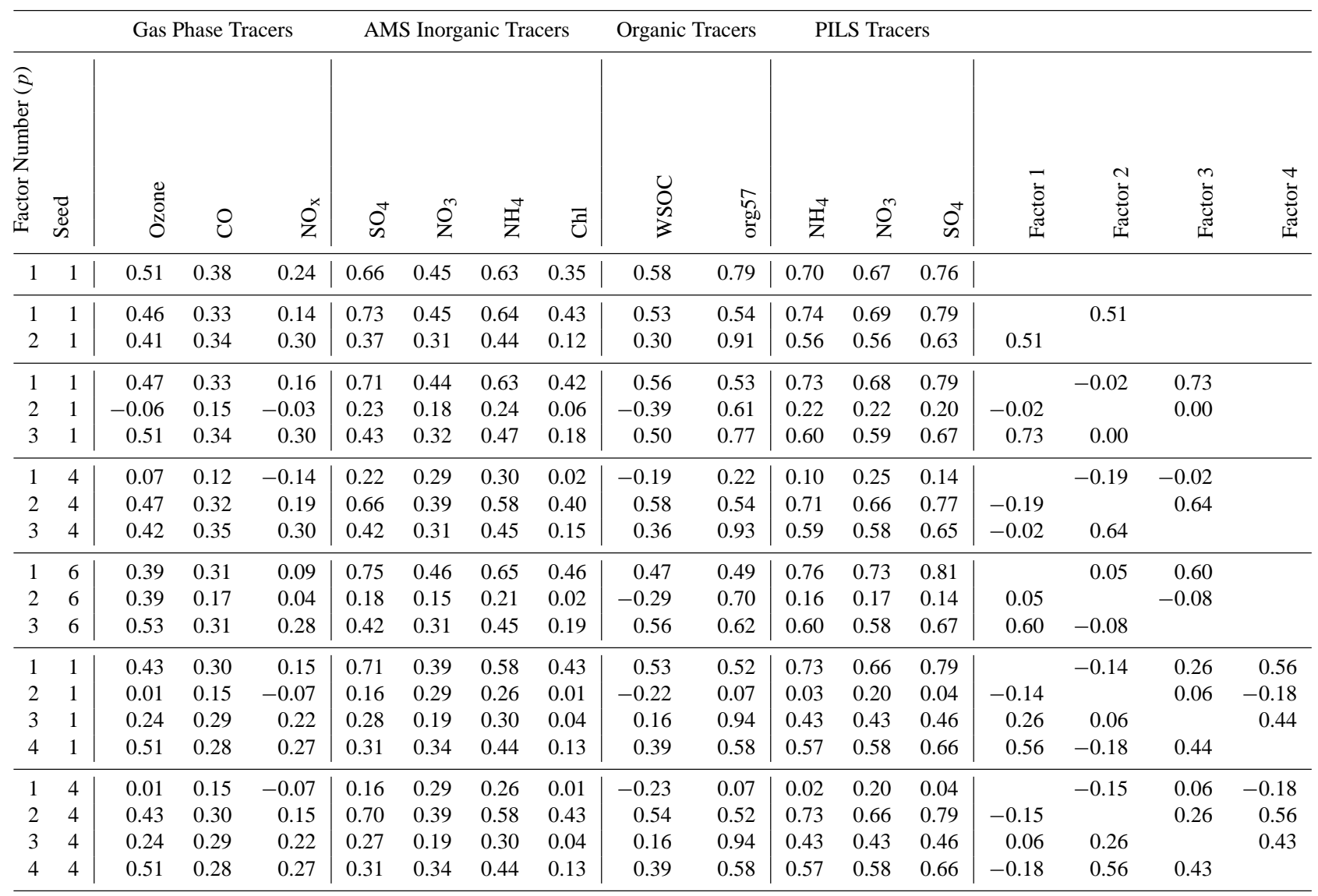

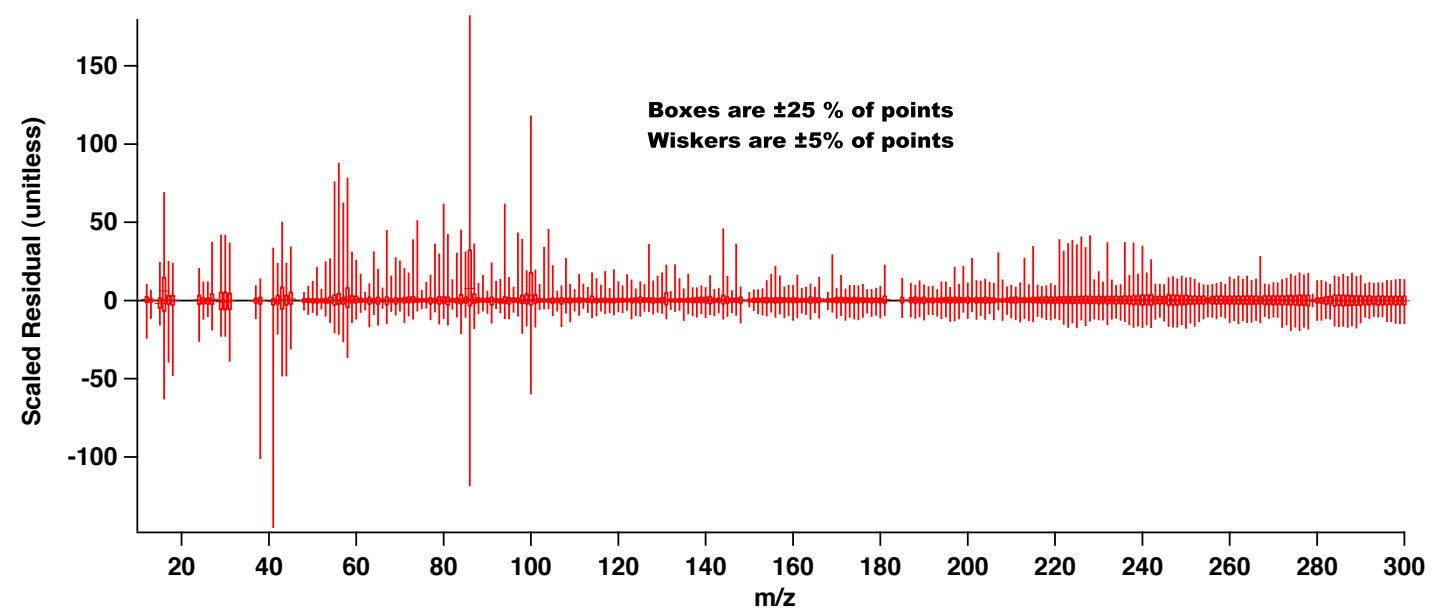

Fig. A4. Scaled residuals for the 3 factor solution ( $\operatorname{seed}=6$ ). 


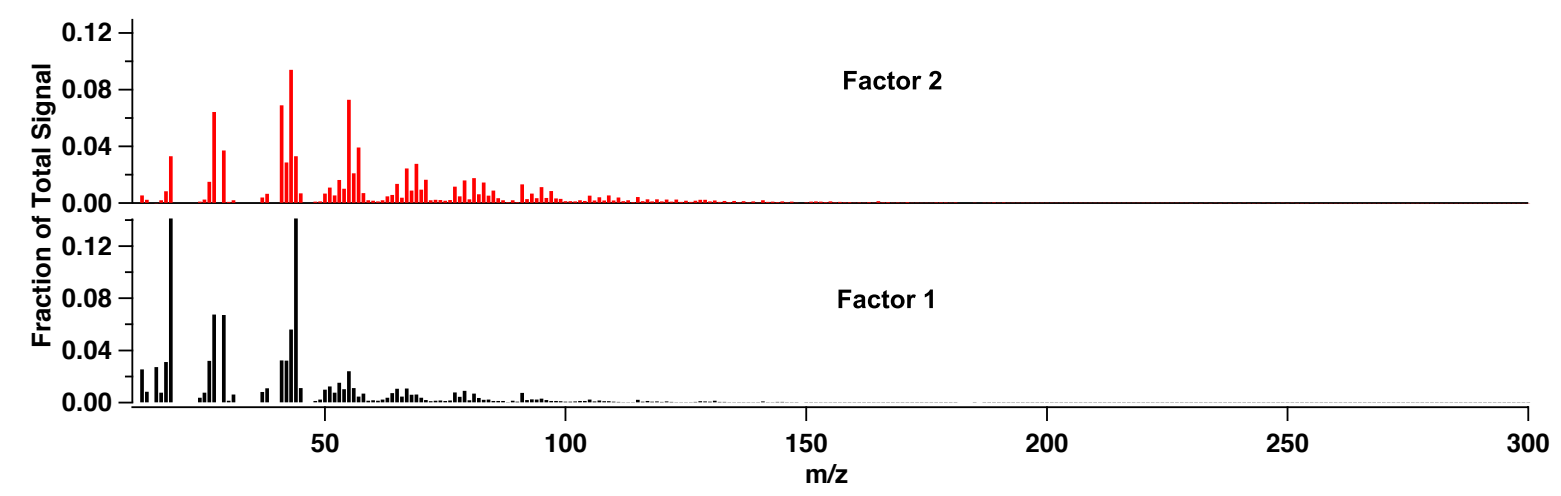

Fig. A5a. Mass spectral profiles for the 2 factor solution.

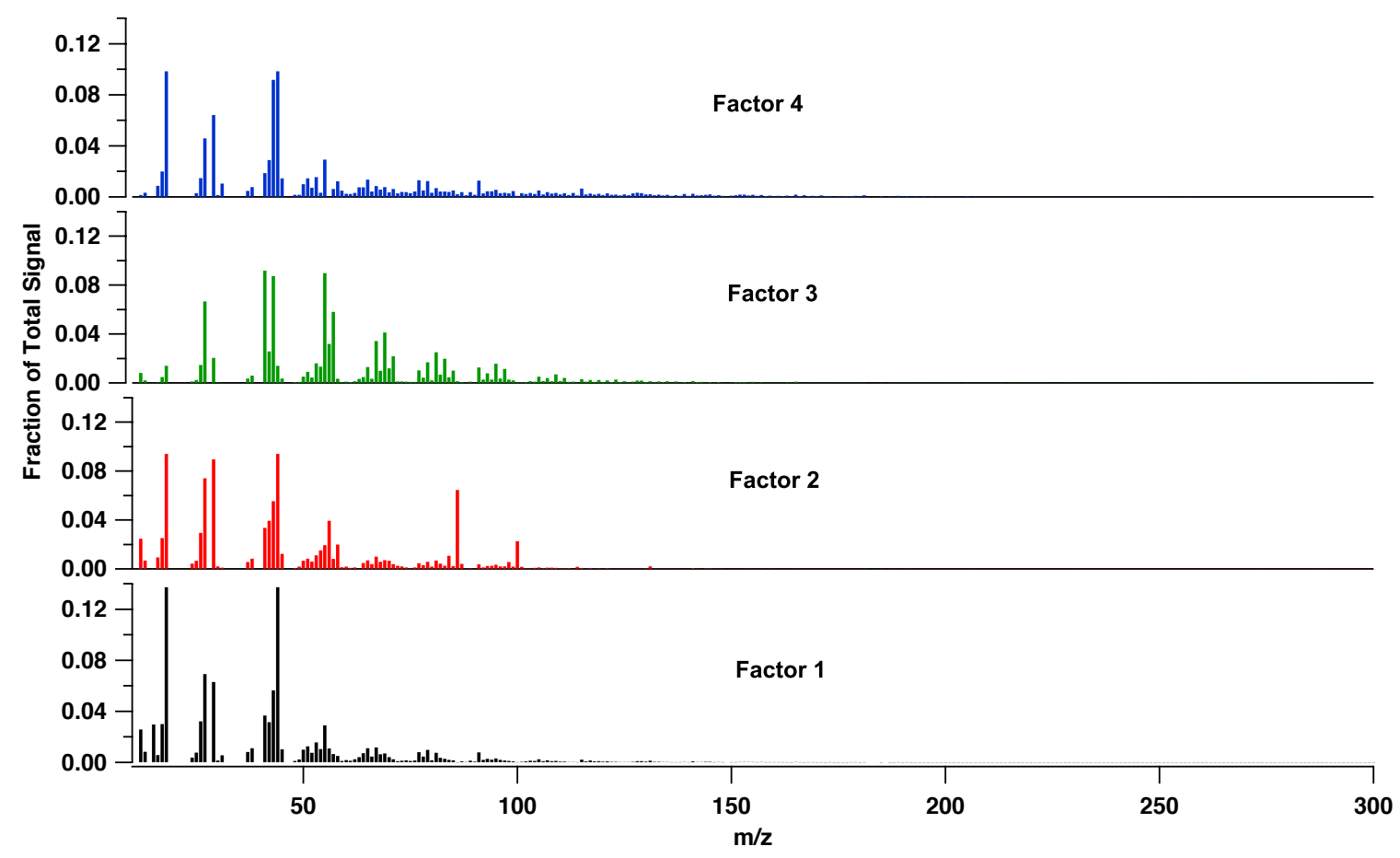

Fig. A5b. Mass spectral profiles for the 4 factor solution. 


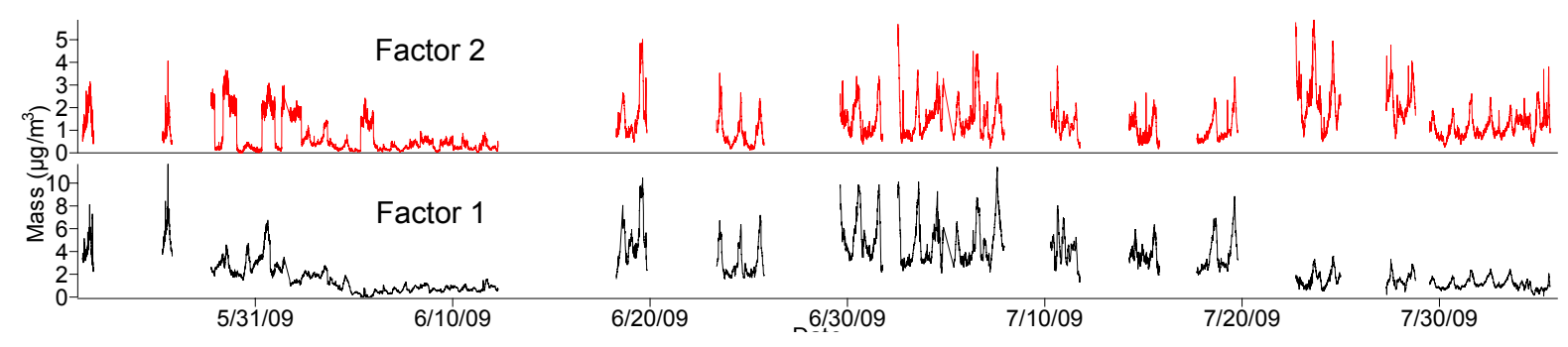

Fig. A6. Time series contributions for the 2-factor solution.

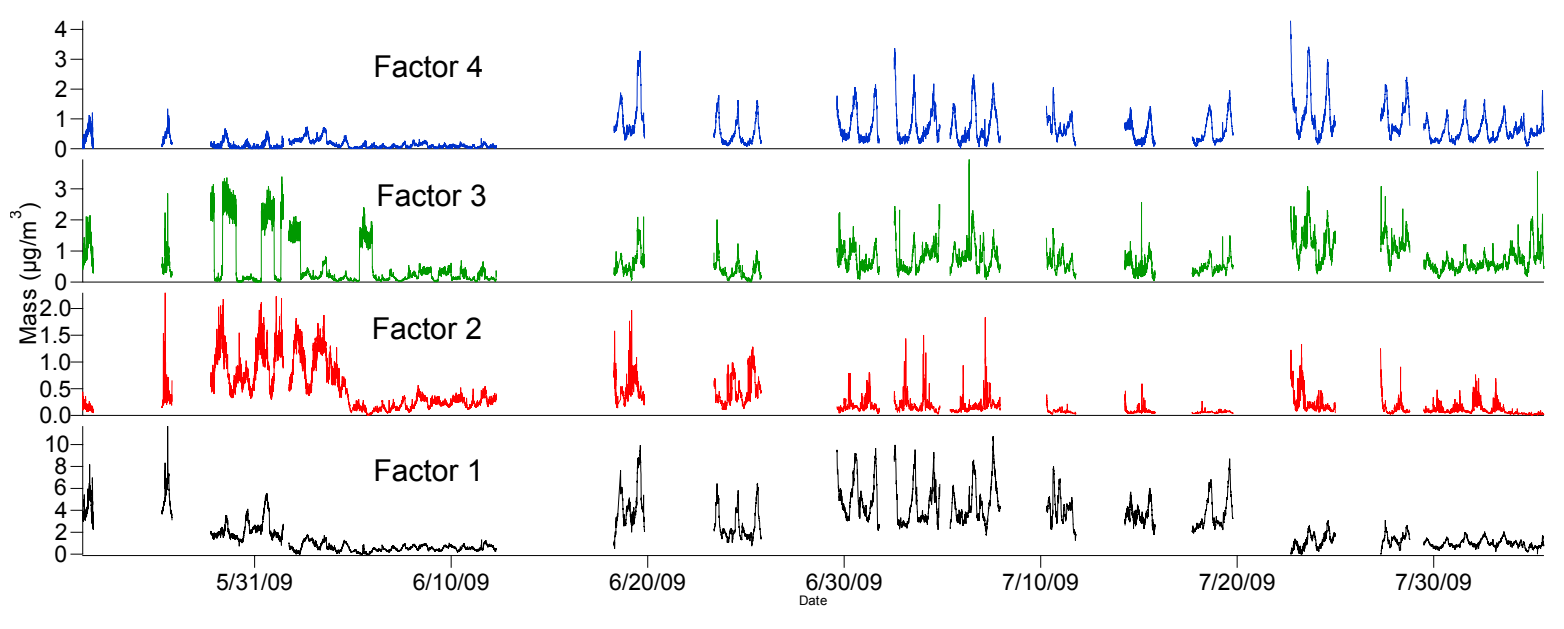

Fig. A7. Time series contributions for the 4-factor solution. 
Acknowledgements. Funding was provided by the Electric Power Research Institute. The authors would like to thank Jason Surratt for his helpful comments and direction. We would also like to thank Eric Edgerton and the SEARCH network for guidance on high-volume filter sampling and for the use of a sampler during PACO.

Edited by: M. C. Facchini

\section{References}

Aiken, A. C., DeCarlo, P. F., Kroll, J. H., Worsnop, D. R., Huffman, J. A., Docherty, K. S., Ulbrich, I. M., Mohr, C., Kimmel, J. R., Sueper, D., Sun, Y., Zhang, Q., Trimborn, A., Northway, M., Ziemann, P. J., Canagaratna, M. R., Onsach, T. B., Alfarra, M. R., Prevot, A. S. H., Dommen, J., Duplissy, J., Metzger, A., Baltensperger, U., and Jimenez, J. L.: O/C and OM/OC ratios of primary, secondary, and ambient organic aerosols with high-resolution time-of-flight aerosol mass spectrometry, Environ. Sci. Technol., 42, 4478-4485, 2008.

Aiken, A. C., Salcedo, D., Cubison, M. J., Huffman, J. A., DeCarlo, P. F., Ulbrich, I. M., Docherty, K. S., Sueper, D., Kimmel, J. R., Worsnop, D. R., Trimborn, A., Northway, M., Stone, E. A., Schauer, J. J., Volkamer, R. M., Fortner, E., de Foy, B., Wang, J., Laskin, A., Shutthanandan, V., Zheng, J., Zhang, R., Gaffney, J., Marley, N. A., Paredes-Miranda, G., Arnott, W. P., Molina, L. T., Sosa, G., and Jimenez, J. L.: Mexico City aerosol analysis during MILAGRO using high resolution aerosol mass spectrometry at the urban supersite (T0) - Part 1: Fine particle composition and organic source apportionment, Atmos. Chem. Phys., 9, 6633-6653, doi:10.5194/acp-9-6633-2009, 2009.

Alfarra, M., Coe, H., Allan, J., Bower, K., Boudries, H., Canagaratna, M., Jimenez, J., Jayne, J., Garforth, A., Li, S., and Worsnop, D. R.: Characterization of urban and rural organic particulate in the Lower Fraser Valley using two aerodyne aerosol mass spectrometers, Atmos. Environ., 38, 5745-5758, 2004.

Allan, J., Bower, K., Coe, H., Boudries, H., Jayne, J., Canagaratna, M., Millet, D., Goldstein, A., Quinn, P., Weber, R., and Worsnop, D.: Submicron aerosol composition at Trinidad Head, California, during ITCT 2K2: its relationship with gas phase volatile organic carbon and assessment of instrument performance, J. Geophys. Res. Atmos., 109, D23S24, doi:10.1029/2003JD004208, 2004a.

Allan, J., Delia, A., Coe, H., Bower, K., Alfarra, M., Jimenez, J., Middlebrook, A., Drewnick, F., Onasch, T., Canagaratna, M., Jayne, J., and Worsnop, D.: A generalised method for the extraction of chemically resolved mass spectra from aerodyne aerosol mass spectrometer data, J. Aerosol Sci., 35, 909-922, doi:10.1016/j.jaerosci.2004.02.007, 2004b.

Ault, A. P., Gaston, C. J., Wang, Y., Dominguez, G., Thiemens, M. H., and Prather, K. A.: Characterization of the single particle mixing state of individual ship plume events measured at the port of Los Angeles, Environ. Sci. Technol., 44(6), 1954-1961, 2010.

AQMD: Historic ozone air quality trends, available at: http://www. aqmd.gov/smog/o3trend.html, last access: August 2010, 2010.

Bahreini, R., Keywood, M., Ng, N., Varutbangkul, V., Gao, S., Flagan, R., Seinfeld, J., Worsnop, D., and Jimenez, J.: Measurements of secondary organic aerosol from oxidation of cy- cloalkenes, terpenes, and m-xylene using an Aerodyne aerosol mass spectrometer, Environ. Sci. Technol., 39, 5674-5688, 2005.

Bein, K. J., Zhao, Y. J., Pekney, N. J., Davidson, C. I., Johnston, M. V., and Wexler, A. S.: Identification of sources of atmospheric PM at the Pittsburgh Supersite - Part II: Quantitative comparisons of single particle, particle number, and particle mass measurements, Atmos. Environ., 40, S424-S444, 2006.

Blumenthal, D., White, W., and Smith, T.: Anatomy of a Los Angeles smog episode: pollutant transport in the daytime sea breeze regime, Atmos. Environ., 12, 893-907, 1978.

Bremner, J., Haub, C., Lee, M., Mather, M., and Zuehlke, E.: World Population Highlights: Key Findings From PRB's 2009 World Population Data Sheet, Population Reference Bureau, available at: www.prb.org, 2009.

Cabada, J. C., Rees, S., Takahama, S., Khlystov, A., Pandis, S. N., Davidson, C. I., and Robinson, A. L.: Mass size distributions and size resolved chemical composition of fine particulate matter at the Pittsburgh supersite, Atmos. Environ., 38, 3127-3141, 2004.

Canagaratna, M., Jayne, J., Jimenez, J., Allan, J., Alfarra, M., Zhang, Q., Onasch, T., Drewnick, F., Coe, H., Middlebrook, A., Worsnop, D. R., and Jimenez, J. L.: Chemical and microphysical characterization of ambient aerosols with the aerodyne aerosol mass spectrometer, Mass Spectrom. Rev., 26, 185-222, 2007.

CARB: iADAM Air Quality Data Statistics, California Air Resources Board, available at: http://www.arb.ca.gov/adam/, 2010.

Chow, J. C., Fujita, E. M., Watson, J. G., Lu, Z. Q., Lawson, D. R., and Asbaugh, L. L.: Evaluation of filter-based aerosol measurements during the 1987 Southern California-Quality Study, Environ. Monit. Assess., 30, 49-80, 1994.

Cocker, D. R., Whitlock, N. E., Flagan, R. C., and Seinfeld, J. H.: Hygroscopic properties of Pasadena, California aerosol, Aerosol Sci. Technol., 35, 637-647, 2001.

Croes, B. E. and Fujita, E. M.: Overview of the 1997 Southern California Ozone Study (SCOS97-NARSTO), Atmos. Environ., 37, S3-S26, 2003.

Cubison, M. J., Ervens, B., Feingold, G., Docherty, K. S., Ulbrich, I. M., Shields, L., Prather, K., Hering, S., and Jimenez, J. L.: The influence of chemical composition and mixing state of Los Angeles urban aerosol on CCN number and cloud properties, Atmos. Chem. Phys., 8, 5649-5667, doi:10.5194/acp8-5649-2008, 2008.

DeCarlo, P. F., Kimmel, J. R., Trimborn, A., Northway, M. J., Jayne, J. T., Aiken, A. C., Gonin, M., Fuhrer, K., Horvath, T., Docherty, K. S., Worsnop, D. R., and Jimenez, J. L.: Fielddeployable, high-resolution, time-of-flight aerosol mass spectrometer, Anal. Chem., 78, 8281-8289, 2006.

DeCarlo, P. F., Dunlea, E. J., Kimmel, J. R., Aiken, A. C., Sueper, D., Crounse, J., Wennberg, P. O., Emmons, L., Shinozuka, Y., Clarke, A., Zhou, J., Tomlinson, J., Collins, D. R., Knapp, D., Weinheimer, A. J., Montzka, D. D., Campos, T., and Jimenez, J. L.: Fast airborne aerosol size and chemistry measurements above Mexico City and Central Mexico during the MILAGRO campaign, Atmos. Chem. Phys., 8, 4027-4048, doi:10.5194/acp-8-4027-2008, 2008.

Denkenberger, K. A., Moffet, R. C., Holecek, J. C., Rebotier, T. P., and Prather, K. A.: Real-time, single-particle measurements of oligomers in aged ambient aerosol particles, Environ. Sci. Technol., 41, 5439-5446, 2007.

Dusek, U., Frank, G. P., Curtius, J., Drewnick, F., Schneider, 
J., Kürten, A., Rose, D., Andreae, M. O., Borrmann, S., and Pöschl, U.: Enhanced organic mass fraction and decreased hygroscopicity of cloud condensation nuclei $(\mathrm{CCN})$ during new particle formation events, Geophys. Res. Lett., 37, L03804, doi:10.1029/2009GL040930, 2010.

Docherty, K. S., Stone, E. A., Ulbrich, I. M., DeCarlo, P. F., Snyder, D. C., Schauer, J. J., Peltier, R. E., Weber, R. J., Murphy, S. M., Seinfeld, J. H., Grover, B. D., Eatough, D. J., and Jimenez, J. L.: Apportionment of primary and secondary organic aerosols in Southern California during the 2005 Study of Organic Aerosols in Riverside (SOAR-1), Environ. Sci. Technol., 42, 7655-7662, 2008.

Drewnick, F., Schwab, J., Hogrefe, O., Peters, S., Husain, L., Diamond, D., Weber, R., and Demerjian, K.: Intercomparison and evaluation of four semi-continuous $\mathrm{PM}_{2.5}$ sulfate instruments, Atmos. Environ., 37, 3335-3350, doi:10.1016/S13522310(03)00351-0, 2003.

Drewnick, F., Hings, S., DeCarlo, P., Jayne, J., Gonin, M., Fuhrer, K., Weimer, S., Jimenez, J., Demerjian, K., Borrmann, S., and Worsnop, D.: A new time-of-flight aerosol mass spectrometer (TOF-AMS) - instrument description and first field deployment, Aerosol Sci. Tech., 39, 637-658, doi:10.1080/02786820500182040, 2005.

Eatough, D. J., Grover, B. D., Woolwine, W. R., Eatough, N. L., Long, R., and Farber, R.: Source apportionment of $1 \mathrm{~h}$ semicontinuous data during the 2005 Study of Organic Aerosols in Riverside (SOAR) using positive matrix factorization, Atmos. Environ., 42, 2706-2719, 2008.

Eldering, A., Cass, G. R., and Moon, K. C.: An Air monitoring network using continuous particle-size distribution monitors - connecting pollutant properties to visibility via mie scattering calculations, Atmos. Environ., 28, 2733-2749, 1994.

Hersey, S. P., Sorooshian, A., Murphy, S. M., Flagan, R. C., and Seinfeld, J. H.: Aerosol hygroscopicity in the marine atmosphere: a closure study using high-time-resolution, multiple-RH DASHSP and size-resolved C-ToF-AMS data, Atmos. Chem. Phys., 9, 2543-2554, doi:10.5194/acp-9-2543-2009, 2009.

Huffman, J., Jayne, J., Drewnick, F., Aiken, A., Onasch, T., Worsnop, D., and Jimenez, J.: Design, modeling, optimization, and experimental tests of a particle beam width probe for the aerodyne aerosol mass spectrometer, Aerosol Sci. Tech., 39, 1143-1163, doi:10.1080/02786820500423782, 2005.

Hughes, L. S., Allen, J. O., Salmon, L. G., Mayo, P. R., Johnson, R. J., and Cass, G. R.: Evolution of nitrogen species air pollutants along trajectories crossing the Los Angeles area, Environ. Sci. Technol., 36, 3928-3935, 2002.

Kautzman, K. E., Surratt, J. D., Chan, M. N., Chan, A. W. H., Hersey, S. P., Chhabra, P. S., Dalleska, N. F., Wennberg, P. O., Flagan, R. C., and Seinfeld, J. H.: Chemical composition of gasand aerosol-phase products from the photooxidation of naphthalene, J. Phys. Chem. A, 114, 913-934, 2010.

Kleeman, M., Hughes, L., Allen, J., and Cass, G.: Source contributions to the size and composition distribution of atmospheric particles: Southern California in September 1996, Environ. Sci. Technol., 33, 4331-4341, 1999.

Kondo, Y., Miyazaki, Y., Takegawa, N., Miyakawa, T., Weber, R. J., Jimenez, J. L., Zhang, Q., and Worsnop, D. R.: Oxygenated and water-soluble organic aerosols in Tokyo, J. Geophys. Res., 112, D01203, doi:10.1029/2006JD007056, 2007.
Lanz, V. A., Alfarra, M. R., Baltensperger, U., Buchmann, B., Hueglin, C., and Prévôt, A. S. H.: Source apportionment of submicron organic aerosols at an urban site by factor analytical modelling of aerosol mass spectra, Atmos. Chem. Phys., 7, 15031522, doi:10.5194/acp-7-1503-2007, 2007.

Liu, D. Y., Prather, K. A., and Hering, S. V.: Variations in the size and chemical composition of nitrate-containing particles in Riverside, CA, Aerosol Sci. Technol., 33, 71-86, 2000.

Lu, R. and Turco, R.: Air pollutant transport in a coastal environment - II. Three-dimensional simulations over Los Angeles Basin, Atmos. Environ., 29, 1499-1518, 1995.

Massling, A., Stock, M., and Wiedensohler, A.: Diurnal, weekly, and seasonal variation of hygroscopic properties of submicrometer urban aerosol particles, Atmos. Environ., 39, 3911-3922, 2005.

Massling, A., Stock, M., Wehner, B., Wu, Z. J., Hu, M., Bruggemann, E., Gnauk, T., Herrmann, H., and Wiedensohler, A.: Size segregated water uptake of the urban submicrometer aerosol in Beijing, Atmos. Environ., 43, 1578-1589, 2009.

Matsui, H., Koike, M., Kondo, Y., Takegawa, N., Kita, K., Miyazaki, Y., Hu, M., Chang, S. Y., Blake, D. R., Fast, J. D., Zaveri, R. A., Streets, D. G., Zhang, Q., and Zhu, T.: Spatial and temporal variations of aerosols around Beijing in summer 2006: model evaluation and source apportionment, J. Geophys. Res. Atmos., 114, D00G13, 2009.

Meier, J., Wehner, B., Massling, A., Birmili, W., Nowak, A., Gnauk, T., Brüggemann, E., Herrmann, H., Min, H., and Wiedensohler, A.: Hygroscopic growth of urban aerosol particles in Beijing (China) during wintertime: a comparison of three experimental methods, Atmos. Chem. Phys., 9, 6865-6880, doi:10.5194/acp-9-6865-2009, 2009.

Modey, W. K., Eatough, D. J., Anderson, R. R., Martello, D. V., Takahama, S., Lucas, L. J., and Davidson, C. I.: Ambient fine particulate concentrations and chemical composition at two sampling sites in metropolitan Pittsburgh: a 2001 intensive summer study, Atmos. Environ., 38, 3165-3178, 2004.

Na, K., Sawant, A. A., Song, C., and Cocker, D. R.: Primary and secondary carbonaceous species in the atmosphere of Western Riverside County, California Atmos. Environ., 38, 1345-1355, 2004.

Ng, N. L., Canagaratna, M. R., Zhang, Q., Jimenez, J. L., Tian, J., Ulbrich, I. M., Kroll, J. H., Docherty, K. S., Chhabra, P. S., Bahreini, R., Murphy, S. M., Seinfeld, J. H., Hildebrandt, L., Donahue, N. M., DeCarlo, P. F., Lanz, V. A., Prévôt, A. S. H., Dinar, E., Rudich, Y., and Worsnop, D. R.: Organic aerosol components observed in Northern Hemispheric datasets from Aerosol Mass Spectrometry, Atmos. Chem. Phys., 10, 46254641, doi:10.5194/acp-10-4625-2010, 2010.

Ng, N. L., Canagaratna, M. R., Jimenez, J. L., Zhang, Q., Ulbrich, I. M., and Worsnop, D. R.: Real-time methods for estimating organic component mass concentrations from aerosol mass spectrometer data, Environ. Sci. Technol., 45, 910-916, doi:10.1021/es102951k, 2011.

Paatero, P.: A weighted non-negative least squares algorithm for three-way "PARAFAC" factor analysis, Chemom. Intell. Lab. Syst., 38, 223-242, 1997.

Paatero, P. and Tapper, U.: Positive matrix factorization - a nonnegative factor model with optimal utilization of error-estimates of data values, Environmetrics, 5, 111-126, 1994. 
Pastor, S. H., Allen, J. O., Hughes, L. S., Bhave, P., Cass, G. R., and Prather, K. A.: Ambient single particle analysis in Riverside, California by aerosol time-of-flight mass spectrometry during the SCOS97-NARSTO, Atmos. Environ., 37, S239-S258, 2003.

Pekney, N. J., Davidson, C. I., Bein, K. J., Wexler, A. S., and Johnston, M. V.: Identification of sources of atmospheric PM at the Pittsburgh Supersite, Part I: single particle analysis and filterbased positive matrix factorization, Atmos. Environ., 40, S411S423, 2006.

Petters, M. D. and Kreidenweis, S. M.: A single parameter representation of hygroscopic growth and cloud condensation nucleus activity, Atmos. Chem. Phys., 7, 1961-1971, doi:10.5194/acp-71961-2007, 2007.

van Pinxteren, D., Bruggemann, E., Gnauk, T., Iinuma, Y., Muller, K., Nowak, A., Achtert, P., Wiedensohler, A., and Herrmann, H.: Size- and time-resolved chemical particle characterization during CAREBeijing-2006: different pollution regimes and diurnal profiles, J. Geophys. Res. Atmos., 114, D00G09, doi:10.1029/2008JD010890, 2009.

Quinn, P., Bates, T., Baynard, T., Clarke, A., Onasch, T., Wang, W., Rood, M., Andrews, E., Allan, J., Carrico, C., Coffman, D., and Worsnop, D. R.: Impact of particulate organic matter on the relative humidity dependence of light scattering: a simplified parameterization, Geophys. Res. Lett., 32(22), L22809, doi:10.1029/2005GL024322, 2005.

Rose, D., Nowak, A., Achtert, P., Wiedensohler, A., Hu, M., Shao, M., Zhang, Y., Andreae, M. O., and Pöschl, U.: Cloud condensation nuclei in polluted air and biomass burning smoke near the mega-city Guangzhou, China - Part 1: Size-resolved measurements and implications for the modeling of aerosol particle hygroscopicity and CCN activity, Atmos. Chem. Phys., 10, 3365-3383, doi:10.5194/acp-10-3365-2010, 2010.

Sawant, A. A., Na, K., Zhu, X., Cocker, K., Butt, S., Song, C., and Cocker III, D. R.: Characterization of $\mathrm{PM}_{2.5}$ and selected gasphase compounds at multiple indoor and outdoor sites in Mira Loma, California, Atmos. Environ., 38, 6269-6278, 2004.

Schauer, J. J., Rogge, W. F., Hildemann, L. M., Mazurek, M. A., and Cass, G. R.: Source apportionment of airborne particulate matter using organic compounds as tracers, Atmos. Environ., 30, 3837-3855, 1996.

Shinozuka, Y., Clarke, A. D., DeCarlo, P. F., Jimenez, J. L., Dunlea, E. J., Roberts, G. C., Tomlinson, J. M., Collins, D. R., Howell, S. G., Kapustin, V. N., McNaughton, C. S., and Zhou, J.: Aerosol optical properties relevant to regional remote sensing of $\mathrm{CCN}$ activity and links to their organic mass fraction: airborne observations over Central Mexico and the US West Coast during MILAGRO/INTEX-B, Atmos. Chem. Phys., 9, 6727-6742, doi:10.5194/acp-9-6727-2009, 2009.

Sorooshian, A., Brechtel, F., Weber, R., Corless, A., Flagan, R., and Seinfeld, J.: Modeling and characterization of a particleinto-liquid sampler (PILS), Aerosol Sci. Technol., 40, 396-409, 2006.

Sorooshian, A., Hersey, S., Brechtel, F., Corless, A., Flagan, R., and Seinfeld, J.: Rapid, size-resolved aerosol hygroscopic growth measurements: differential aerosol sizing and hygroscopicity spectrometer probe (DASH-SP), Aerosol Sci. Technol., 42, 445464, 2008.

Stanier, C., Khlystov, A., and Pandis, S.: Nucleation events during the Pittsburgh Air Quality Study: description and relation to key meteorological, gas phase, and aerosol parameters special issue of aerosol science and technology on findings from the fine particulate matter supersites program, Aerosol Sci. Technol., 38, 253-264, 2004.

Stone, E. A., Snyder, D. C., Sheesley, R. J., Sullivan, A. P., Weber, R. J., and Schauer, J. J.: Source apportionment of fine organic aerosol in Mexico City during the MILAGRO experiment 2006, Atmos. Chem. Phys., 8, 1249-1259, doi:10.5194/acp-81249-2008, 2008.

Sullivan, A., Weber, R., Clements, A., Turner, J., Bae, M., and Schauer, J.: A method for on-line measurement of water-soluble organic carbon in ambient aerosol particles: results from an urban site, Geophys. Res. Lett., 31, L13105, doi:10.1029/2004GL019681, 2004.

Sullivan, A., Peltier, R., Brock, C., De Gouw, J., Holloway, J., Warneke, C., Wollny, A., and Weber, R.: Airborne measurements of carbonaceous aerosol soluble in water over Northeastern United States: method development and an investigation into water-soluble organic carbon sources, J. Geophys. Res., 111, 114, 2006.

Surratt, J., Gomez-Gonzalez, Y., Chan, A., Vermeylen, R., Shahgholi, M., Kleindienst, T., Edney, E., Offenberg, J., Lewandowski, M., Jaoui, M., Maenhaut, W., Claeys, M., Flagan, R. C., and Seinfeld, J. H.: Organosulfate formation in biogenic secondary organic aerosol, J. Phys. Chem. A, 112, 8345-8378, 2008.

Swietlicki, E., Hansson, H., Hameri, K., Svenningsson, B., Massling, A., McFiggans, G., McMurry, P., Petaja, T., Tunved, P., Gysel, M., Topping, D., Weingartner, E., Baltensperger, U., Rissler, J., Wiedensohler, A., and Kulmala, M.: Hygroscopic properties of submicrometer atmospheric aerosol particles measured with H-TDMA instruments in various environments - a review, Tellus B, 60, 432-469, 2008.

Tiitta, P., Miettinen, P., Vaattovaara, P., Joutsensaari, J., Pet, T., Virtanen, A., Raatikainen, T., Aalto, P., Portin, H., Romakkaniemi, S., Kokkolab, H., Lehtinena, E. J., Markku, K., and Laaksonena, A.: Roadside aerosol study using hygroscopic, organic and volatility TDMAs: characterization and mixing state, Atmos. Environ., 44, 976-986, 2010.

Turpin, B. J. and Huntzicker, J. J.: Secondary formation of organic aerosol in the Los-Angeles Basin - a descriptive analysis of organic and elemental carbon concentrations, Atmos. Environ. A, 25, 207-215, 1991.

Turpin, B. J. and Lim, H.-J.: Species contributions to $\mathrm{PM}_{2.5}$ mass concentrations: revisiting common assumptions for estimating organic mass, Aerosol Sci. Technol., 35, 602-610, 2001.

Ulbrich, I. M., Canagaratna, M. R., Zhang, Q., Worsnop, D. R., and Jimenez, J. L.: Interpretation of organic components from Positive Matrix Factorization of aerosol mass spectrometric data, Atmos. Chem. Phys., 9, 2891-2918, doi:10.5194/acp-9-2891-2009, 2009.

Ulbrich, I. M., Lechner, M., and Jimenez, J. L.: AMS Spectral Database, available at: http://cires.colorado.edu/jimenez-group/ AMSsd/, 2009.

Wang, J., Cubison, M. J., Aiken, A. C., Jimenez, J. L., and Collins, D. R.: The importance of aerosol mixing state and size-resolved composition on $\mathrm{CCN}$ concentration and the variation of the importance with atmospheric aging of aerosols, Atmos. Chem. Phys., 10, 7267-7283, doi:10.5194/acp-10-7267-2010, 2010. 
Watson, J. G., Chow, J. C., Lu, Z. Q., Fujita, E. M., Lowenthal, D. H., Lawson, D. R., and Ashbaugh, L. L.: Chemical mass-balance source apportionment of $\mathrm{PM}_{(10)}$ during the Southern California Air-Quality Study, Aerosol Sci. Technol., 21, 136, 1994.

Wex, H., McFiggans, G., Henning, S., and Stratmann, F.: Influence of the external mixing state of atmospheric aerosol on derived CCN number concentrations, Geophys. Res. Lett., 37, L10805, doi:10.1029/2010GL043337, 2010.

Wittig, A. E., Anderson, N., Khlystov, A. Y., Pandis, S. N., Davidson, C., and Robinson, A. L.: Pittsburgh air quality study overview, Atmos. Environ., 38, 3107-3125, 2004.

Yue, D. L., Hu, M., Wu, Z. J., Wang, Z. B., Guo, S., Wehner, B., Nowak, A., Achtert, P., Wiedensohler, A., Jung, J., Kim, Y. J., and Liu, S.: Characteristics of aerosol size distributions and new particle formation in the summer in Beijing, J. Geophys. Res. Atmos., 114, D00G12, doi:10.1029/2008JD010894, 2009.

Zhang, X. and McMurray, S.: Mixing characteristics and water content of submicron aerosols measured in Los Angeles and at the Grand Canyon, Atmos. Environ. A, 27, 1593-1607, 1993.
Zhang, Q., Alfarra, M., Worsnop, D., Allan, J., Coe, H., Canagaratna, M., and Jimenez, J.: Deconvolution and quantification of hydrocarbon-like and oxygenated organic aerosols based on aerosol mass spectrometry, Environ. Sci. Technol., 39, 49384952, 2005.

Zhang, Q., Jimenez, J. L., Canagaratna, M. R., Allan, J. D., Coe, H., Ulbrich, I., Alfarra, M. R., Takami, A., Middlebrook, A. M., Sun, Y. L., Dzepina, K., Dunlea, E., Docherty, K., DeCarlo, P. F., Salcedo, D., Onasch, T., Jayne, J. T., Miyoshi, T., Shimono, A., Hatakeyama, S., Takegawa, N., Kondo, Y., Schneider, J., Drewnick, F., Borrmann, S., Weimer, S., Demerjian, K., Williams, P., Bower, K., Bahreini, R., Cottrell, L., Griffin, R. J., Rautiainen, J., Sun, J. Y., Zhang, Y. M., and Worsnop, D. R.: Ubiquity and dominance of oxygenated species in organic aerosols in anthropogenically-influenced Northern Hemisphere midlatitudes, Geophys. Res. Lett., 34, L13801, doi:10.1029/2007GL029979, 2007. 